\title{
Correlation between concrete cracks and corrosion characteristics of steel reinforcement in pre-cracked plain and fibre-reinforced concrete beams
}

\author{
E. Chen · Carlos G. Berrocal · Ingemar Löfgren · Karin Lundgren
}

Received: 14 October 2019/Accepted: 24 February 2020/Published online: 6 March 2020

(C) The Author(s) 2020

\begin{abstract}
This paper presents results on corrosion characteristics of 66 rebars extracted from un- and precracked plain concrete and fibre-reinforced concrete (FRC) beams suffering from corrosion for more than 3 years. The influences of fibre reinforcement, flexural cracks, corrosion-induced cracks and loading condition on the maximum local corrosion level (defined as the maximum cross-sectional area loss percentage) and pit morphology were examined. With 3D-scanning, the corrosion characteristics were analysed, and pit types were classified based on the maximum local corrosion level and geometric parameters of pits. Corrosion pits were observed near some flexural cracks, while the bars at other cracks were free from corrosion. Most rebars in FRC had less maximum local corrosion level than those in plain concrete under the same loading condition and maximum flexural crack width. However, the maximum local corrosion level was not dependent on the maximum flexural crack width $(0.1$ and $0.4 \mathrm{~mm})$. Longitudinal cracks (corrosion-induced cracks) aggravated the total steel loss and changed the pit morphology by promoting the pit length development. However, longitudinal cracks
\end{abstract}

E. Chen $(\bowtie)$ C C. G. Berrocal · I. Löfgren · K. Lundgren Division of Structural Engineering, Chalmers University of Technology, 41296 Göteborg, Sweden

e-mail: teresa.chen@chalmers.se

C. G. Berrocal · I. Löfgren

Thomas Concrete Group AB, Södra Vägen 28, 41254 Göteborg, Sweden did not always form, even with severe pitting corrosion. A hypothesis about the time-dependent interplay between transverse and longitudinal cracks and corrosion development was proposed. Further studies on predicting the pitting corrosion evolution and experimental work on specimens exposed for longer periods are needed to understand and quantify the long-term durability of concrete structures reinforced with both conventional reinforcing bars and fibres.

Keywords Pitting corrosion - 3D-scanning - Fibrereinforced concrete $\cdot$ Transverse cracks $\cdot$ Corrosioninduced cracks

\section{List of symbols}

$A_{0}^{\text {min }} \quad$ Uncorroded cross-sectional area at the minimum cross-section

$A_{c}^{\text {min }} \quad$ Remaining cross-sectional area at the minimum cross-section

$A_{c} \quad$ Remaining area at each cross-section

$V_{p} \quad$ Pit volume

$d_{0} \quad$ Nominal diameter of steel reinforcement

$k \quad$ Coefficient taking into account the removal of mill-scale during sand-blasting

$l_{p} \quad$ Pit length

$m_{0} \quad$ Initial weight of reinforcement before casting

$m_{f} \quad$ Final weight of reinforcement after corrosion

$r_{0} \quad$ Nominal radius of steel reinforcement

$x_{p} \quad$ Pit depth

$x_{u} \quad$ Equivalent uniform corrosion depth 
$x_{u, \text { ave }}$ Equivalent uniform corrosion depth for the corrosion level $\mu_{\mathrm{ave}, l_{p}}$

$x_{u, \max }$ Equivalent uniform corrosion depth for the corrosion level $\mu_{\max }$

$\alpha_{\text {ave }} \quad$ Pitting factor calculated from $x_{u, \text { ave }}$

$\alpha_{\max } \quad$ Pitting factor calculated from $x_{u, \max }$

$\mu_{\mathrm{ave}, l_{p}} \quad$ Average corrosion level within the pit length

$\mu_{\max } \quad$ Maximum local corrosion level, defined as the maximum cross-sectional area loss percentage

$\mu_{g} \quad$ Global corrosion level of the whole bar, measured from weight loss

PL Plain reinforced concrete, i.e. conventional reinforced concrete

ST Concrete reinforced with conventional steel bars and steel fibres

HY Concrete reinforced with conventional steel bars and hybrid fibres (steel fibres and synthetic fibres)

SY Concrete reinforced with conventional steel bars and synthetic fibres

\section{Introduction}

Corrosion of reinforcement in concrete structures is a major problem affecting the durability of reinforced concrete (RC) structures, particularly for those in marine environments or exposed to de-icing salts [1]. External agents such as chloride, $\mathrm{CO}_{2}$, oxygen, and water, can penetrate concrete cover. When the chloride concentration near the rebar surface reaches a critical value or the carbonation front advances over time to the rebar's depth, the passive film on the reinforcement is destroyed, after which corrosion initiates [2].

Moreover, in practice RC structures inevitably have cracks, originating from such things as shrinkage, thermal gradients and/or mechanical loading. These cracks provide preferential paths for the ingress of external agents [3,4], which shortens the corrosion initiation period and induces localised corrosion near the cracks [5, 6]. However, the long-term impact of cracks on the corrosion propagation phase has not been clarified and is still under debate [7]. As discussed in the state-of-the-art review [7], some studies reported that the corrosion rate increased with the crack width $[6,8,9]$, while other studies indicated that cracks did not enhance the corrosion process or that the enhancing effect diminished with time $[10,11]$.

Although the importance of crack width on reinforcement corrosion is not completely clear, to limit the risk of corrosion, current codes $[12,13]$ dictate the minimum cover depth and maximum allowable crack width, based on the class of environment aggressiveness. The restrictive requirement of controlling crack width for civil engineering structures exposed to marine environments or de-icing salts (such as harbour piers or bridges) often results in congested reinforcement layouts. These are costly and difficult to handle on-site. In such cases, an attractive alternative could be the use of fibre reinforcement combined with conventional reinforcement. Fibres are an effective means of crack control through fibre bridging [14]. They can also improve the mechanical performance of concrete structures [15]. Nevertheless, the corrosion performance of conventional reinforcement in FRC in chloride environments is not yet fully understood. In [16], fibre-reinforced cementitious composites (FRCC) with a 1.5\% fibre volume fraction were found to delay the corrosion initiation and reduce the corrosion amount, compared to plain mortar under the same impressed voltage. Further, it was shown in [17] that bars in FRC with a $1.5 \%$ fibre volume fraction had longer corrosion initiation times and a lower active corrosion rate compared to bars in plain concrete at the same flexural load.

An earlier study by the authors [18] investigated the effect of various types of fibres (with a volume fraction of $<1 \%$ ) on the corrosion initiation time of steel bars in pre-cracked beams. Unlike other studies [16, 17], the maximum surface crack width produced by threepoint bending was kept the same for plain RC and FRC beams. This made it possible to examine the effect on steel corrosion of crack characteristics such as crack pattern and internal crack morphology in FRC. The impact of the width of surface crack was also studied by setting the target crack width (maximum flexural crack width) to $0.1,0.2,0.3$, and $0.4 \mathrm{~mm}$. Experimental results showed a tendency towards earlier initiation of corrosion, with increasing crack widths. A small improvement (in terms of delayed corrosion initiation) was observed when fibres were added. In the subsequent study [19], the flexural behaviour of corroded plain RC and FRC beams (among the specimens in 
[18]) was examined. FRC beams were found to display higher residual load capacity at reinforcement yielding than plain RC beams, whereas the relative loss of load capacity (the loss of load normalised by the load on reference beams) as a function of the maximum local corrosion level was similar to that seen in plain RC beams [19]. However, the relative contribution of the fibres to the residual capacity of FRC beams and mechanical behaviour of corroded rebars could not be investigated specifically, as it was not possible to evaluate the mechanical behaviour of those rebars accurately after the flexural capacity tests. Following the tests, the corrosion level of critical rebar segments was evaluated using 3D-scanning [19]. However, no clear trend was identified in maximum local corrosion levels regarding (1) fibre addition, (2) targeted crack widths of 0.2 and $0.3 \mathrm{~mm}$ and (3) loading type. This was partly due to the limited number of specimens. Thus, further studies on the correlation between concrete cracks and the corrosion behaviour of rebars in plain RC and FRC beams should focus on achieving a better understanding of the influence of cracks and fibres on the corrosion process.

The present study is a continuation of previous ones $[18,19]$. The purpose was to examine the effect of cracks and fibres on the corrosion characteristics of rebars from the remaining uncracked and cracked specimens, with target crack widths of 0.1 and $0.4 \mathrm{~mm}$ prepared in [18]. In particular, a 3D-scanning technique was used to obtain the pit morphology. This enabled detailed geometrical parameters to be determined for each pit (including the maximum crosssectional area loss, pit depth, pit length and pit volume) and represent the corrosion condition. When discussing the influence on reinforcement corrosion of such factors as concrete binder type and cracking $[6,8,20,21]$, most existing studies use a definition of "corrosion level" that refers to either "corrosion rate" (measured using electrochemical techniques), or "corrosion amount" (often calculated as the weight loss). However, the corrosion rate measured from electrochemical methods may give inaccurate estimation on the local corrosion state if the actual extent of the anodic area in the rebar is not known [22, 23]; this may render the conclusions regarding various factors on the corrosion propagation not reliable. Further, it is the pit characteristics that determine the consequences of steel corrosion, including the mechanical properties of corroded rebars, corrosion-induced cover cracking and concrete-steel bond behaviour and, hence, the overall structural performance. Understanding the influence of various factors on pit morphology will increase the reliability of conclusions as to their effects on structural durability and safety.

\section{Experimental programme}

\subsection{Specimens description}

The specimens in this study were $1100 \mathrm{~mm}$ long beams with cross-sectional dimensions of $180 \times 100 \mathrm{~mm}^{2}$. Each beam was reinforced with three $\Phi 10 \mathrm{~mm}$ "as-received" ribbed rebars, positioned with a clear concrete cover of $30 \mathrm{~mm}$. The end of the bars embedded in the beam had a distance of $30 \mathrm{~mm}$ away from the beam end whereas the other end of the bars stuck out $50 \mathrm{~mm}$ to enable an electrical connection for the corrosion monitoring equipment. The geometry of the specimens, including the reinforcement layout, is illustrated in Fig. 1. Four different series of specimens were used, one without fibre reinforcement referred to as "plain" (PL) series, and three FRC series with different types of fibre reinforcement, referred to as "steel" (ST), "hybrid" (HY) and "synthetic" (SY) series. The types of fibres used for the different FRC series were $35 \mathrm{~mm}$ end-hooked steel fibres for the ST series, $30 \mathrm{~mm}$ straight polyvinyl alcohol (PVA) fibres for the SY series and a combination of steel fibres and $18 \mathrm{~mm}$ long PVA fibres for the HY series. A self-compacting concrete mix with the same water/cement ratio of 0.47 was used for all the series. The mix proportions are given in Table 1. A total of 54 beams specimens were cast in 2013. After casting, the beams were covered with a polyethylene sheet. After $24 \mathrm{~h}$, they were demoulded. Subsequently, the beams were wetted and wrapped in geotextile and plastic sheets at room temperature until the age of 10 weeks. After that, the beams were preloaded to induce cracking under different loading conditions and subsequently exposed to chlorides except six of the beams kept uncracked and stored in potable water for use as reference samples. In 2017, 32 beams (including the reference beams, some of the uncracked beams and cracked beams with a target crack width of 0.2 and $0.3 \mathrm{~mm}$ ) were tested structurally to assess their residual flexural behaviour [19]. The remaining 22 beams (including the uncracked 

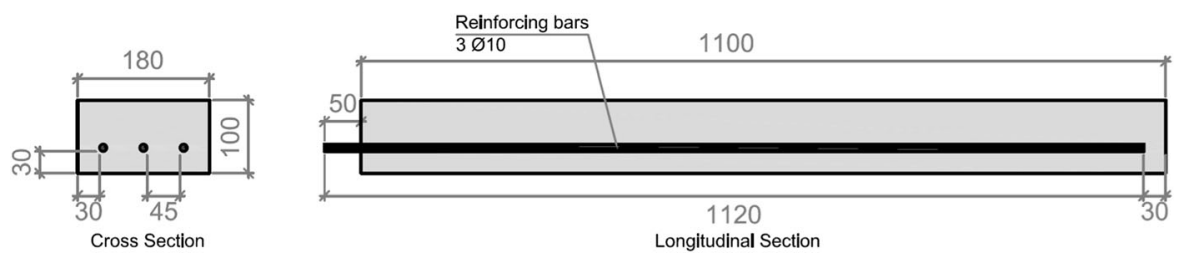

Fig. 1 Specimen geometry

Table 1 Concrete mix proportions, in $\left(\mathrm{kg} / \mathrm{m}^{3}\right)$

\begin{tabular}{|c|c|c|c|c|}
\hline \multicolumn{5}{|l|}{ Component } \\
\hline \multicolumn{4}{|c|}{ Cement (CEM I 42.5 N SR 3 MH/LA) } & 360 \\
\hline \multicolumn{4}{|l|}{ Limestone filler (Limus 40) } & 165 \\
\hline \multicolumn{4}{|l|}{ Fine aggregate (sand $0 / 4$ ) } & 770 \\
\hline \multicolumn{4}{|c|}{ Coarse aggregate (crushed 5/16) } & 833 \\
\hline \multicolumn{4}{|l|}{ Effective water } & 169 \\
\hline \multicolumn{4}{|c|}{ Superplasticizer-Glenium 51/18 } & 5.76 \\
\hline \multicolumn{4}{|l|}{ Air entrainer-MicroAir 105} & 0.72 \\
\hline Fibre content (vol\%) & $\mathrm{PC}$ & ST & HY & SY \\
\hline Steel—Dramix ${ }^{\circledR} 65 / 35-B N$ & - & 0.5 & 0.35 & - \\
\hline PVA-Kuralon ${ }^{\mathrm{TM}}$ RFS400 & - & - & 0.15 & - \\
\hline PVA-Kuralon ${ }^{\mathrm{TM}}$ RF4000 & - & - & - & 0.75 \\
\hline
\end{tabular}

beams and cracked beams with a target crack width of 0.1 and $0.4 \mathrm{~mm}$ ) were investigated in this study.

\subsection{Load and exposure conditions}

The four conditions considered were: (a) uncracked specimens, which were never loaded, (b) specimens that were loaded only once to induced cracking, (c) specimens subjected to five load cycles to promote greater damage at the rebar-concrete interface and (d) specimens initially pre-cracked and subsequently reloaded with a sustained load to keep the cracks open. When referring to their loading conditions, the beams are denoted throughout the paper as "uncracked", "unloaded", "cyclic" and "loaded".

The specimens were pre-loaded under three-point bending at age 10 weeks, up to the target crack of 0.1 , $0.2,0.3$, and $0.4 \mathrm{~mm}$. During the pre-loading procedure, the widest crack formed on each beam was measured using a crack detection microscope, at $20 \times$ magnification and $0.02 \mathrm{~mm}$ resolution, to determine when the target crack width was reached. However, in one of the ST beams under "cyclic" loading, the maximum crack width reached $0.8 \mathrm{~mm}$ instead of the target crack width of $0.4 \mathrm{~mm}$. It should be noted that, in order to reach the same target crack width under the same loading type, the load applied to FRC series was always greater than that for plain series, see [18]. Upon unloading, the cracks closed to a certain degree and the remaining surface crack width ranged between 0.02 and $0.06 \mathrm{~mm}$, for both the plain and fibre-reinforced specimens. The beams subjected to sustained loading were paired using a clamping setup. This was to keep the target crack width as the widest crack opening during the pre-loading procedure.

The beams were partially immersed in a highly concentrated sodium chloride solution $(16.5 \% \mathrm{NaCl})$, with approximately three quarters of the beam length submerged. The chloride exposure was conducted cyclically, with 2-week wetting cycles followed by 2-week drying cycles under laboratory conditions $\left(20.5 \pm 3.6{ }^{\circ} \mathrm{C}\right.$ and $\left.45 \pm 15 \% \mathrm{RH}\right)$. Corrosion potentials were monitored hourly with an embedded $\mathrm{MnO}_{2}$ reference electrode to determine the corrosion initiation time. Corrosion rates were measured based on the galvanostatic pulse technique every 2 weeks in the beginning and every 6 weeks during the last 18 months of the exposure period. Those results have been reported by the authors in previous work [18].

After 3 years' exposure, all the specimens were removed from the tanks and stored in the laboratory. The reinforcement corrosion continued naturally during storage, as the specimens were fully contaminated by chlorides and showing active corrosion. The corrosion rates were not measured during the storing period; nevertheless, a lower corrosion rate was expected compared to that during the exposure period.

Table 2 summarises the specimens used in this study. Some beams (including the uncracked and six cracked PL beams, and two cracked ST beams) were taken out for testing after being stored in the laboratory for 18 months, while the other 13 beams were tested 
Table 2 Summary of specimens' conditions

\begin{tabular}{|c|c|c|c|c|c|c|c|c|c|c|}
\hline \multicolumn{3}{|c|}{$\begin{array}{c}\text { Load } \\
\text { conditions }\end{array}$} & Series & \multicolumn{2}{|c|}{$\begin{array}{l}\text { Target } \\
\text { crack } \\
\text { widths } \\
(\mathrm{mm})\end{array}$} & $\begin{array}{l}\text { No. of } \\
\text { beams }\end{array}$ & $\begin{array}{c}\text { Pre- } \\
\text { loading } \\
\text { time }\end{array}$ & $\begin{array}{l}\text { Exposure } \\
\text { period }\end{array}$ & $\begin{array}{l}\text { Storing } \\
\text { period } \\
\text { before } \\
\text { testing }\end{array}$ & $\begin{array}{l}\text { Crack documentation } \\
\text { before testing }\end{array}$ \\
\hline \multirow{4}{*}{\multicolumn{3}{|c|}{ Uncracked }} & PL & \multicolumn{2}{|c|}{ - } & 1 & \multirow{13}{*}{$\begin{array}{c}10 \text {-week } \\
\text { age }\end{array}$} & \multirow{13}{*}{3 years } & 18 months & $\begin{array}{l}\text { only crack pattern on } \\
\text { tension surface }\end{array}$ \\
\hline & & & ST & \multicolumn{2}{|c|}{ - } & 1 & & & 24 months & $\begin{array}{l}\text { all crack pattern and } \\
\text { crack width }\end{array}$ \\
\hline & & & HY & \multicolumn{2}{|c|}{ - } & 1 & & & 24 months & $\begin{array}{l}\text { all crack pattern and } \\
\text { crack width }\end{array}$ \\
\hline & & & SY & \multicolumn{2}{|c|}{ - } & 1 & & & 24 months & $\begin{array}{l}\text { all crack pattern and } \\
\text { crack width }\end{array}$ \\
\hline \multirow{9}{*}{ 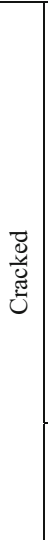 } & \multirow{7}{*}{ 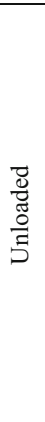 } & \multirow{4}{*}{ 苛 } & PL & 0.1 & 0.4 & 2 & & & 18 months & $\begin{array}{l}\text { only crack pattern on } \\
\text { tension surface }\end{array}$ \\
\hline & & & ST & 0.1 & 0.4 & 2 & & & 18 months & $\begin{array}{l}\text { only crack pattern on } \\
\text { tension surface }\end{array}$ \\
\hline & & & HY & 0.1 & 0.4 & 2 & & & 24 months & $\begin{array}{l}\text { all crack pattern and } \\
\text { crack width }\end{array}$ \\
\hline & & & SY & 0.1 & 0.4 & 2 & & & 24 months & $\begin{array}{l}\text { all crack pattern and } \\
\text { crack width }\end{array}$ \\
\hline & & \multirow{3}{*}{$\begin{array}{l}\frac{3}{0} \\
0 \\
0 \\
n\end{array}$} & PL & 0.1 & 0.4 & 2 & & & 18 months & $\begin{array}{l}\text { only crack pattern on } \\
\text { tension surface }\end{array}$ \\
\hline & & & ST & 0.1 & $\begin{array}{c}0.4 \\
(0.8)\end{array}$ & 2 & & & 24 months & $\begin{array}{l}\text { all crack pattern and } \\
\text { crack width }\end{array}$ \\
\hline & & & HY & 0.1 & 0.4 & 2 & & & 24 months & $\begin{array}{l}\text { all crack pattern and } \\
\text { crack width }\end{array}$ \\
\hline & \multirow{2}{*}{\multicolumn{2}{|c|}{ Loaded }} & PL & 0.1 & 0.4 & 2 & & & 18 months & $\begin{array}{l}\text { only crack pattern on } \\
\text { tension surface }\end{array}$ \\
\hline & & & ST & 0.1 & 0.4 & 2 & & & 24 months & $\begin{array}{l}\text { all crack pattern and } \\
\text { crack width }\end{array}$ \\
\hline
\end{tabular}

Note: specimens tested after 18-month and 24-month storage in the laboratory following the exposure period are differentiated by $\square$ and $\square$.

after 24 months' storage. The 6-month time difference between extraction of the rebars may have had minor influence on the total corrosion, but the corrosion characteristics were unlikely to have changed under laboratory conditions in such a short time. This influence is therefore ignored.

\subsection{Crack mapping}

Before extracting bars from the beams, both the flexural cracks and corrosion-induced cracks were mapped. The crack widths of six cracked PL beams and two cracked ST beams were not recorded, whereas the crack widths of other beams were measured with the microscope, as noted in Table 2.

\subsection{Corrosion characteristics evaluation}

After mapping the cracks on the beam surfaces, the beams were broken with a jackhammer and the bars carefully removed. Before cleaning the bars, pit locations and general corrosion regions were measured preliminarily by visual inspection of surface corrosion products. This is because extremely shallow corrosion sites are not easily detected once rust is removed. The corrosion locations were further confirmed and adjusted as necessary, after rust removal by sand-blasting.

The pit locations were identified as positions where the corrosion depth was obviously greater than the surrounding region of rebar surface. The general corrosion regions referred to locations where corrosion products were deposited on the rebar surface but with no obvious localised cavity. Indeed, numerous very tiny pits existed in the general corrosion region but none had developed into an obvious localised pit.

\subsubsection{Sand-blasting and gravimetrical measurements}

The corroded bars were cleaned with sand-blasting to remove corrosion products and adhered concrete. The initial weight of "as-received" bars before casting and 
final weight of the clean corroded bars were measured using a scale accurate to $0.01 \mathrm{~g}$. The global corrosion level was determined as the ratio between the gravimetrical loss to the initial weight of the bar, according to Eq. (1):

$\mu_{g}=\frac{k \times m_{0}-m_{f}}{k \times m_{0}}$

where $\mu_{g}$ is the global corrosion level, $m_{0}$ and $m_{f}$ are the initial and final steel weights and $k$ is a parameter which takes into account the removal of mill-scale from the initial weight during sand-blasting. The parameter $k$ is taken as 0.9978 , which was determined based on the average weight loss of 15 non-corroded, "as-received" bars subjected to mechanical cleaning with wire-bristle brushes to remove mill-scale [19].

\subsubsection{D-scanning technique}

After sand-blasting and weight measurements, each bar was cut into two or three segments with an electric rebar cutter. The cutting sections were selected to get a segment with the most severe pit included in the middle region (referred to as "critical segment") and with a constant length of $500 \mathrm{~mm}$. A few bars presented more than one pit in relatively close proximity and with similar severity. The critical segments of such bars were cut to a length of $550 \mathrm{~mm}$ to accommodate both pits within the same segment. Bar selections to cut for the uncracked beams were made differently, as their most severe pit was close to the bar-end embedded in the concrete. However, the end corrosion was not considered in this study; the remaining segment of rebar with the most severe pitting was evaluated instead.

The scan was carried out using a portable Handy Scan $700^{\mathrm{TM}}$ laser scanner from Creaform. This equipment features an accuracy of up to $20 \mu \mathrm{m}$ and a maximum spatial resolution of the generated point cloud of $0.05 \mathrm{~mm}$. Mounted to a fixture outfitted with reference scanning targets, the bar was scanned by swiping the scanner manually around it at an appropriate distance. The surface of the bar was reconstructed with a 3D triangular mesh of the point cloud generated in the scanner's software. This mesh was repaired in the GOM Inspect software by filling in small holes and removing noise points. A new point cloud was then generated from the repaired mesh for further analysis, using Matlab 2015b commercial software.

The corrosion evaluation procedures are illustrated by the example in Fig. 2. Figure $2 \mathrm{a}$ shows the 3D surface mesh of the scanned bar, whereas Fig. $2 b$ shows the longitudinal variation of cross-sectional area $A_{c}$ along the bar, obtained via the methodology described in [24]. The regular variation of crosssectional area in Fig. $2 b$ is due to the transverse ribs on the bar surface. The 3D coordinates of points composing the bar surface are also shown in a $2 \mathrm{D}$ plot, with the colour representing the radius of every point, as shown in Fig. 2c. The colour scale showing the magnitude of radius (in $\mathrm{mm}$ ) appears in the legend on the right of Fig. 2c. The pit location can be clearly identified from the blue range. The pit length $l_{p}$ is the measurement of the pit along the rebar axis, as shown in Fig. 2c.

To evaluate the corrosion penetration depth (the radius loss) and cross-sectional area loss in the pit, the uncorroded segment covering a complete interval of transverse-rib variation was first identified. An iterative process developed in [19] was used for each section in the pit, to find its original uncorroded section. This involved comparing the healthy part of the corroded section with each section in the uncorroded segment. The original uncorroded section was regarded as the one with the shortest distance to the healthy part of the corroded section, through a set of rigid body transformations (translation and rotation).

The cross-section with the minimum area is marked by a dashed line in Fig. 2c. The appearance of the minimum cross-section with its original uncorroded section is shown in Fig. 2d. The maximum local corrosion level $\mu_{\max }$ is defined as the area loss percentage at the minimum cross-section:

$\mu_{\max }=\frac{A_{0}^{\min }-A_{c}^{\min }}{A_{0}^{\min }}$

where $A_{0}^{\min }$ and $A_{c}^{\mathrm{min}}$ are the uncorroded and remaining cross-sectional areas at the minimum cross-section, respectively. Adding the volume loss between two consecutive cross-sections along the pit length $l_{p}$ gives the approximate total volume loss in the pit:

$V_{p}=\sum_{i=1}^{N-1} \frac{1}{2}\left[\left(A_{0}^{i+1}-A_{c}^{i+1}\right)+\left(A_{0}^{i}-A_{c}^{i}\right)\right] \Delta l$ 
(a)

(b)

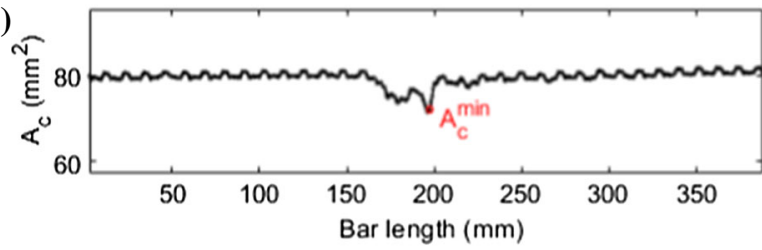

(c)

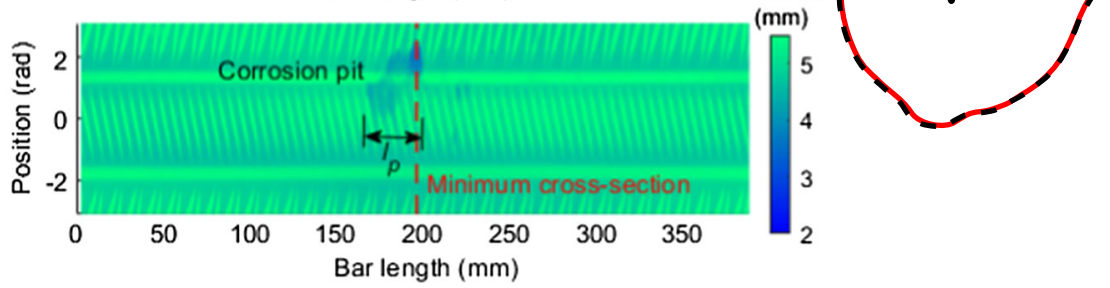

Fig. 2 Example illustrating corrosion evaluation from 3Dscanning: a 3D surface mesh in GOM inspect; b longitudinal variation of the cross-sectional area along the scanned length;

where $\Delta l$ is the interval distance between two consecutive cross-sections (which is a constant value), $A_{0}^{i}$ and $A_{c}^{i}$ are the original and remaining area of the $i$ th crosssection in the pit and $N$ is the total number of crosssections within the pit length $l_{p}$.

The pit dept $x_{p}$ is defined as the maximum radius loss at the minimum cross-section:

$x_{p}=\max \left(r_{o}(j)-r(j)\right)$

where $r_{0}(j)$ and $r(j)$ are the original and final radii at point $j$ on the minimum cross-section.

\section{Classification of pit morphology}

To show how pit morphology is influenced by cracks, loading condition and fibres in the following sections, the pits have been classified according to their geometric characteristics. In the general field of metal corrosion, pit shapes are usually described as conical, hemispherical and saucer-shaped, but they may be completely irregular [25]. Figure 17 in the Appendix shows the common pit shapes for steel and many associated alloys, with the characteristic descriptions for each type. The pit shapes found on 66 bars in this study belong to the "elliptical" and "shallow, wide" types in Fig. 17, with the exception of two special pits which showed the "subsurface" shape. Six types of pit were classified from the parameters of maximum local corrosion level $\mu_{\max }$, pit depth $x_{p}$ and pit length $l_{p}$ c $2 \mathrm{D}$ plot of the bar surface with colour scale showing the magnitude of radius; $\mathbf{d}$ residual and original cross-sectional appearance at the minimum cross-section

(illustrated in Table 3). Colours representing the pit types in Table 3 will be used in the figures below to show the pit types.

Three intervals of the maximum local corrosion level were defined: $\mu_{\max } \leq 5 \%, 5 \%<\mu_{\max } \leq 10 \%$, and $\mu_{\max }>10 \%$ corresponding to "light", "moderate", and "severe" corrosion, respectively. Furthermore, the pit depth and pit length relative to the nominal radius $r_{0}$ and nominal diameter $d_{0}$ of steel bars were used to reflect pit morphology. Type 1 represents tiny pits with $\mu_{\max } \leq 5 \%, x_{p}<r_{0} / 5$ and $l_{p}<d_{0} / 2$. Usually, multiple tiny pits could be found, albeit isolated from each other. For Types 2 and 3, the pitting level is moderate with $5 \%<\mu_{\max } \leq 10 \%$ and $x_{p}<r_{0} / 3$, but Type 2 refers to small pits isolated from each other, while Type 3 describes multiple small pits concentrated (or connected) in the continuous long region of length $l_{p}>2.5 d_{0}$. For Types 4,5 and 6 , the corrosion level is regarded as severe, with $\mu_{\max }>10 \%$. Type 4 is characterised by shallow pit depth $x_{p}<r_{0} / 3$ but longer pit length $l_{p}>2.5 d_{0}$, which is close to the shape "shallow, wide" in Fig. 17. Type 5 is characterised by both long pit length and (locally) greater pit depth, with either an elliptical pit shape embedded in a long pit or an elliptical pit located next to a long pit. Type 6 is characterised by a greater pit depth $x_{p}>r_{0} / 3$ but short pit length $l_{p}<2.5 d_{0}$, showing a typical "elliptical" shape. 
Table 3 Pit morphology classification

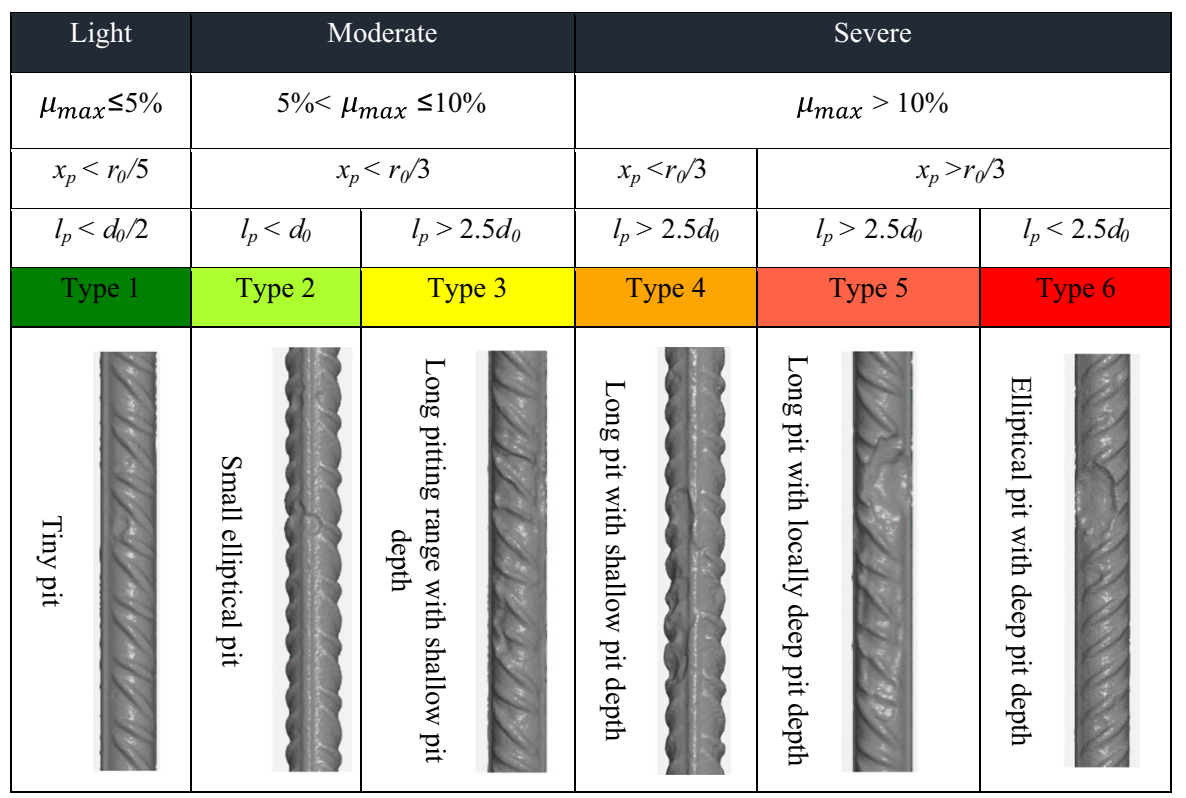

$r_{0}$ and $d_{0}$ are the nominal radius and diameter of rebar

\section{Results and discussions}

4.1 Overview of crack pattern and corrosion
pattern

\subsubsection{Location of cracks and pits}

The crack pattern of concrete surface and corrosion pattern of bars were drawn simultaneously, so as to view the correlation between their locations. Figure 3 illustrates the crack pattern on the tension surface (the surface under tension during three-point bending) and corrosion pattern of plain series under the "uncracked", "unloaded", "cyclic", and "loaded" conditions, with $0.4 \mathrm{~mm}$ target crack. The mix series, loading condition, and target crack width are included in the name of each specimen label. The four load conditions "uncracked", "unloaded", "cyclic", and "loaded" are represented by "N", "U", "C", and "L" respectively. For example, PL-N represents the uncracked plain series beam, PL-U0.4 represents the plain series beam with "unloaded" condition and $0.4 \mathrm{~mm}$ target crack. Figure 4 shows the crack- corrosion pattern of steel fibre, hybrid fibre and synthetic fibre series under the "unloaded" condition, with $0.4 \mathrm{~mm}$ target crack.

All the bars, including those in uncracked beams, were corroded. Corrosion in the "uncracked" beams was light for all mix series but many of the rebars in "uncracked" beams (see PL-N in Fig. 3) showed severe pitting corrosion at the end of the bar embedded in concrete (see Fig. 18a in the Appendix). In cracked beams, light to severe pitting corrosion was found. Pitting corrosion was usually accompanied by general corrosion in the surrounding region. An example of this appears in Fig. 18b. As seen in Figs. 3 and 4, several pits were formed on separate sites of a bar, with most pits located at the flexural cracks. However, some pits were located at a short distance from the transverse cracks. It is noteworthy that in approximately half of the flexural cracks, no corrosion was found. This is probably due to the mechanism described in [26], which suggests that corrosion is induced at the widest crack or weakest position first, which delays and suppresses corrosion in other cracks. 
PL-N

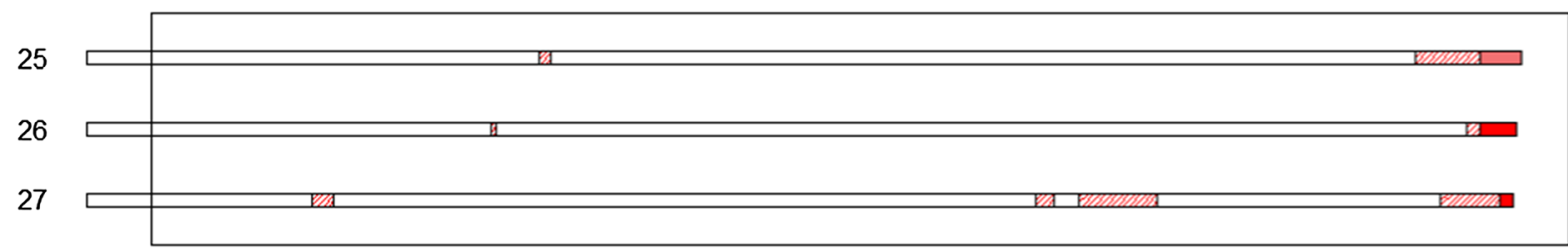

PL-U0.4

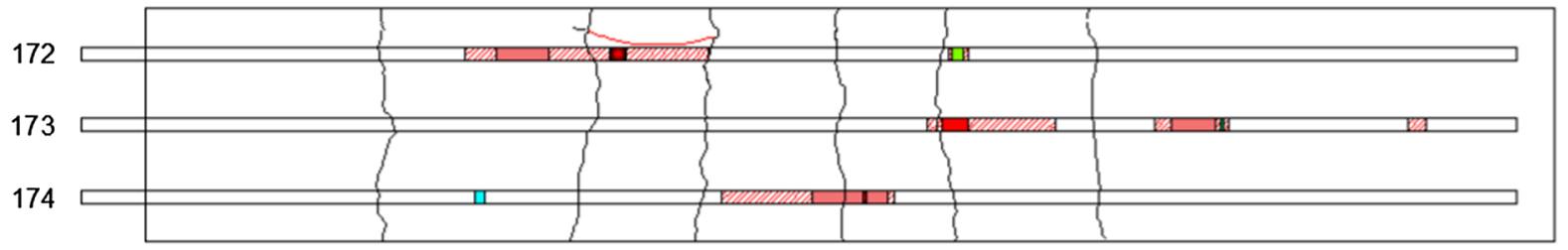

\section{PL-C0.4}

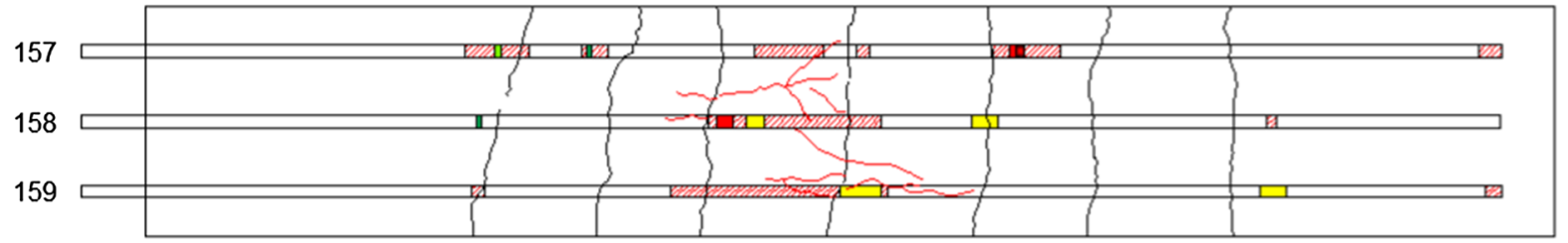

PL-L0.4

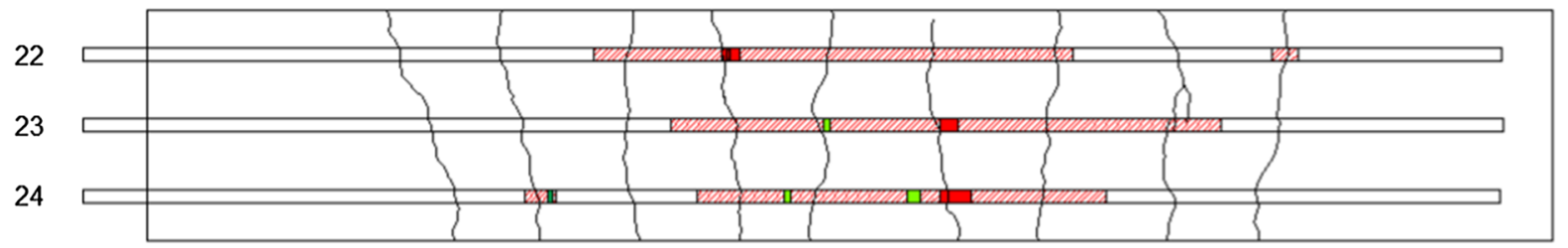

Fig. 3 Crack-corrosion pattern for PL series under the "uncracked", "unloaded", "cyclic" and "loaded" conditions, with $0.4 \mathrm{~mm}$ target crack width (shading represents general corrosion, while solid colours represent pitting corrosion with the

\subsubsection{Rust stains and fibre corrosion}

In most cracked beams, rust stains were found near some corrosion-induced cracks (also commonly called longitudinal or splitting cracks), but no cracks were fully filled with corrosion products. For the fibrereinforced series including steel fibres (ST and HY series), rust stains were distributed at numerous spots on the beam surface due to fibre corrosion, but no corrosion could be found on steel fibres embedded in the cover. It has been found that steel fibres have better corrosion resistance than reinforcement bars. This is probably due to there being fewer defects on the fibre colour corresponding to the pit types defined in Table 3. Flexural and corrosion cracks are indicated by black and red lines respectively)

surface and a more uniform fibre-matrix interface [27]. However, the long-term corrosion resistance and corrosion behaviour of steel fibres across cracks need further investigation, especially when the crack widths become very large.

\subsubsection{Crack characteristics}

It was observed that some flexural cracks (less than $0.02 \mathrm{~mm}$ width) were partially or fully healed, or filled with white material. They may have been healed by the hydrated products or infilled with salt crystals. 
ST-U0.4

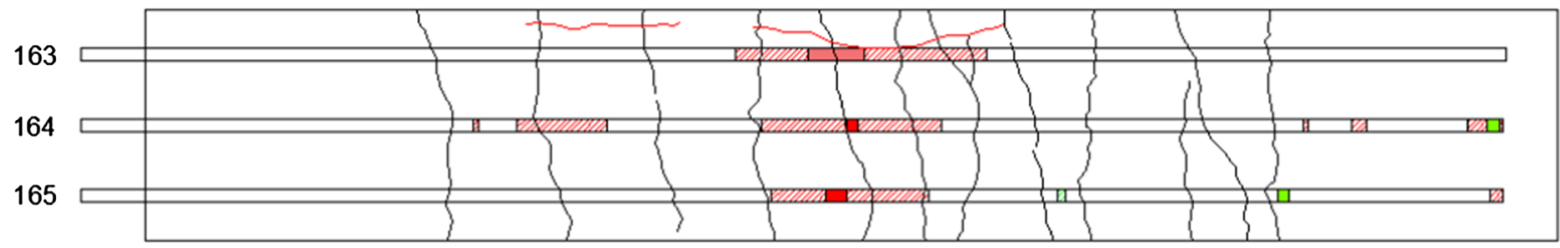

HY-U0.4
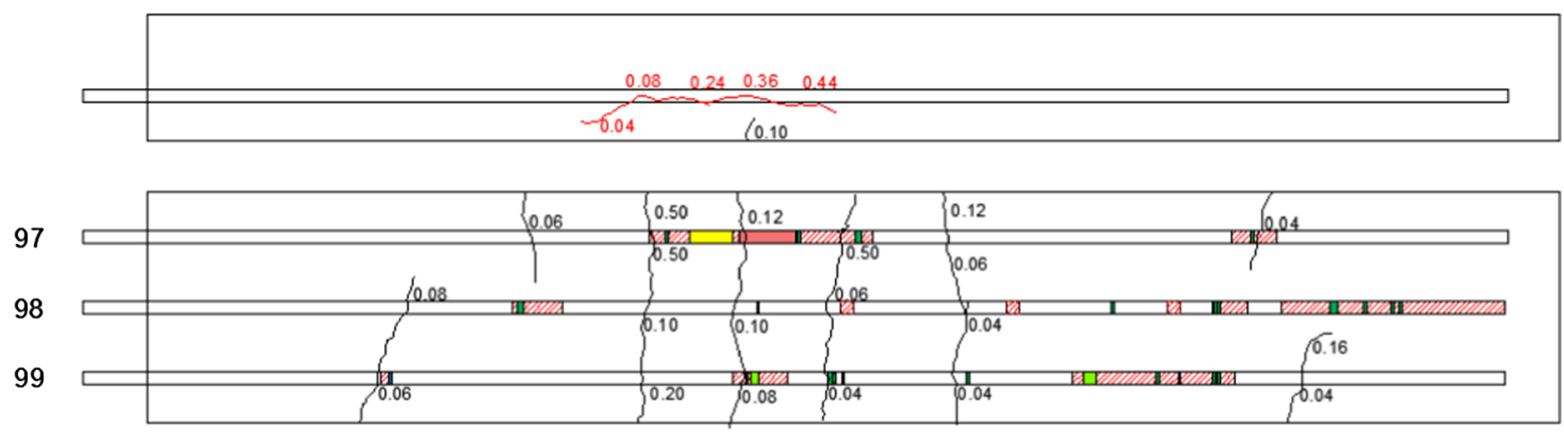

SY-U0.4
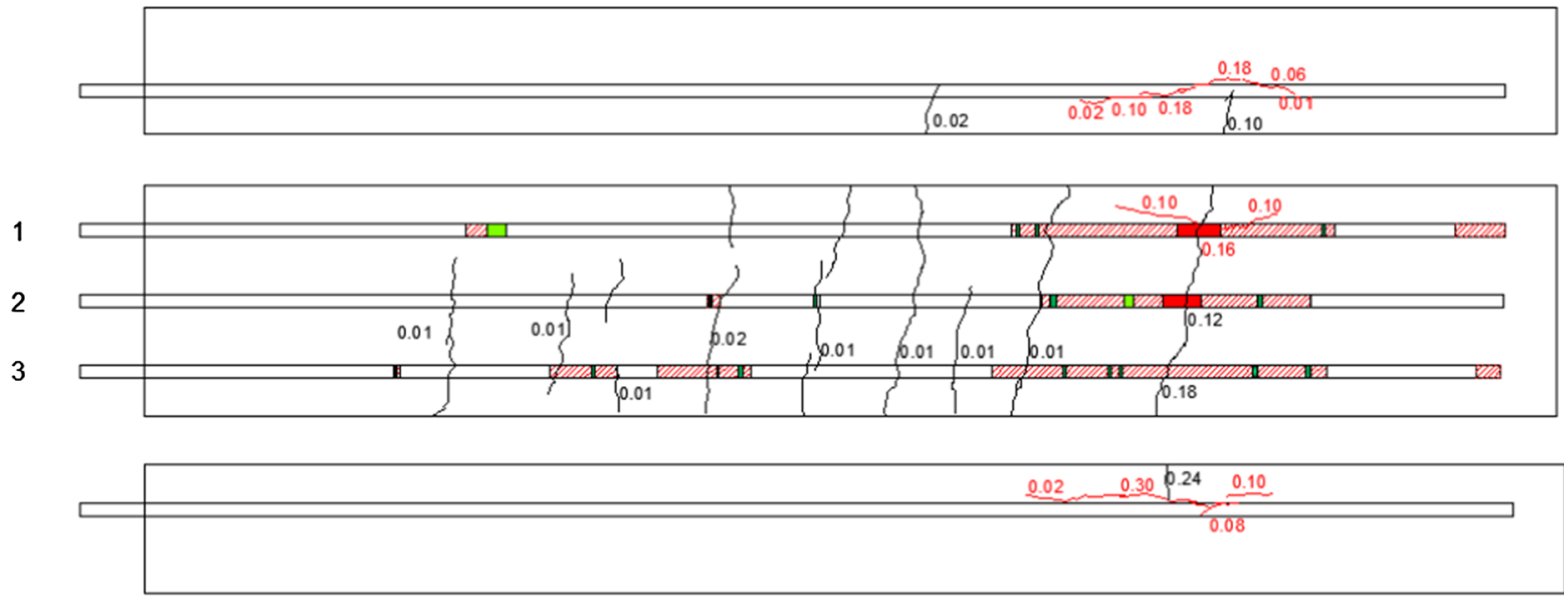

Fig. 4 Crack-corrosion pattern for ST series, HY series and SY series under the "unloaded" condition, with 0.4 mm target crack width

These fine cracks were also traced in the crackcorrosion pattern drawings of Figs. 3 and 4.

For the same loading condition, there were a few more flexural cracks in the fibre-reinforced series than the plain series, such as beams under "unloaded" condition with $0.4 \mathrm{~mm}$ target crack width shown in Figs. 3 and 4. In the previous studies [5, 28], increasing crack frequency decreased the local corrosion rate at each corroding spot, because the crack distance limited the cathodic area available to contribute to the macro-cell current. The flexural crack spacing on beams in this study varied between 40 to $110 \mathrm{~mm}$, and the average crack spacing in fibre series beams was shorter. Since the flexural crack spacing on one beam was not uniform and the difference in the average crack spacing between plain series and fibre-reinforced series was small (less than $2 \times$, see Figs. 3 and 4), the influence of crack spacing on the corrosion level of each pit along a rebar was not examined. Only the local corrosion level of the most severe pit along each rebar was focused in this study. 
Corrosion-induced cracks were found in most beams. They were short in length, localised at severe pits and most of their widths were greater than those of the flexural cracks, as observed in Fig. 4. The flexural cracks crossing the longitudinal cracks were found to have greater widths than other flexural cracks (ones that did not cross corrosion-induced cracks). Thus, the flexural cracks most likely opened due to the creation of longitudinal cracks under corrosion expansion.

\subsubsection{Mapping cracks and the cross-sectional area variation}

To examine the correlation between cracks and pit morphology, the crack widths, longitudinal variation of the remaining cross-sectional area of rebar and the pit morphology were mapped in the same plot. Figure 5 gives three examples of severe pits exhibiting different shapes, with the pit parameters $\left(\mu_{\max }, V_{p}\right.$, and $l_{p}$ ) marked. From the definition given in Table 3, the pit in Fig. 5a is Type 6, being of elliptical shape and short pit length, while the pits in Fig. 5b, c are Type 5, as they are both long and deep. The pit length $l_{p}$ and pit volume $V_{p}$ increase from Fig. 5a-c. The extent (including length and width) of corrosion-induced cracks also increases from Fig. 5a-c, with the respective maximum crack widths being $0.02,0.04$ and $0.24 \mathrm{~mm}$. However, the maximum local corrosion level $\mu_{\max }$ did not follow this increasing order from Fig. 5a-c; the value for Fig. 5b was the greatest, with the values for Fig. 5a-c close behind. The maximum local corrosion level did not seem clearly dependent on longitudinal cracks. Moreover, an association can be identified between the extent of longitudinal cracks and the length and volume of pits. Although it is unknown whether longitudinal cracks are induced by long pits first or vice versa, there is likely a correlation. This will be further discussed in Sect. 4.4.

\subsection{Pitting corrosion parameters}

\subsubsection{Correlation between the global corrosion level and maximum local corrosion level}

The global corrosion level was less than $1.6 \%$ for all bars, as the pitting corrosion only affected a small fraction of the rebar and the general corrosion was almost negligible. On the other hand, the maximum local corrosion level ranged from 0 to $34 \%$. Figure 6 shows the correlation between the global corrosion level and maximum local corrosion level of all bars. The maximum local corrosion level is obviously greater than the global corrosion level for all bars but, otherwise, no correlation can be found. Points with similar global corrosion levels may have major differences in the maximum local corrosion levels. This indicates that, for the bars in this study, the pitting corrosion level cannot be deduced from the global corrosion level, which was also concluded in [29].

\subsubsection{Pitting factor}

To characterise the localised level of a corrosion pit, the pitting factor or pitting concentration factor $\alpha$, was calculated. This is defined as the ratio of maximum pit depth $x_{p}$ to the penetration depth $x_{u}$ corresponding to homogeneous corrosion for the same amount of iron lost [29-31]. In most of the literature, the area loss is usually obtained from the total mass or volume loss per unit length using the gravimetrical method. This assumes the area loss of every cross-section along the measured length to be uniform. Mass loss is measured either for the entire rebar [32] or for short offcuts [10]. Contrary to the traditional gravimetrical method, 3Dscanning enables the obtention of area loss at every cross-section. For pitting corrosion with the area loss at every cross-section inside the pit being different, using area loss at the minimum cross-section and the average area loss of the pit would result in different values of $x_{u}$. Figure 7 plots the correlation between the maximum local corrosion level $\mu_{\max }$ and average corrosion level within the pit length $\mu_{\mathrm{ave}, l_{p}}$. As can be expected, $\mu_{\max }$ is greater than $\mu_{\mathrm{ave}, l_{p}}$. The values of $\mu_{\mathrm{ave}, l_{p}}$ for most pits are less than $15 \%$, except that of three Type 6 pits which exhibit $\mu_{\text {ave }, l_{p}}$ values greater than $20 \%$. Those three pits have a large area loss at every cross-section within the pit. Additionally, the average corrosion level of most pits with maximum local corrosion level $\mu_{\max }$ within $10-25 \%$ is close to $10 \%$. This means averaging the area loss of all crosssections within the pit would not accurately reveal the maximum local corrosion level.

The equivalent uniform corrosion depth, calculated from the maximum cross-sectional area loss $\mu_{\max }$ and average area loss in the pit $\mu_{\mathrm{ave}, l_{p}}$ is noted as $x_{u, \max }$ and $x_{u, \text { ave }}$ respectively, as given in Eqs. (5) and (6): 


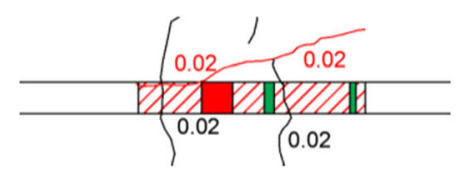

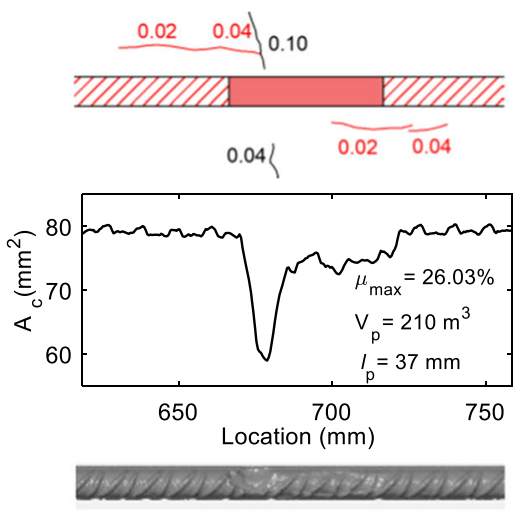

(b)
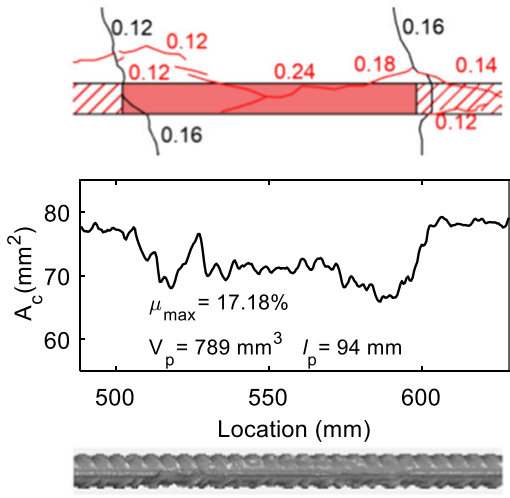

(c)
Fig. 5 Mapping cracks and longitudinal variation of the crosssectional area: a one rebar in HY-C0.4; b one rebar in HY-C0.1; c one rebar in ST-L0.1. Note: the horizontal axis "location" is

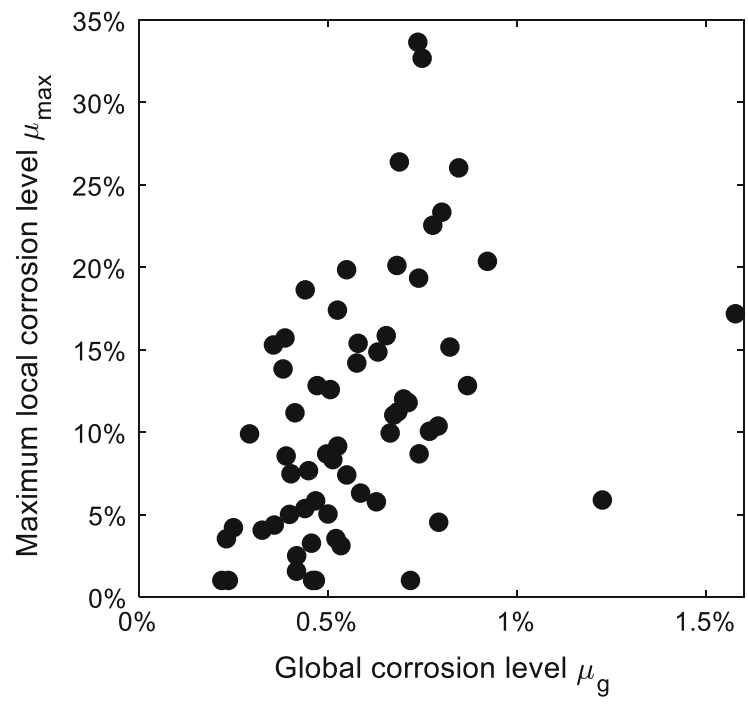

Fig. 6 Maximum local corrosion level versus global corrosion level

$$
\begin{aligned}
& x_{u, \max }=\frac{d_{0}}{2}\left(1-\sqrt{1-\mu_{\max }}\right) \\
& x_{u, \text { ave }}=\frac{d_{0}}{2}\left(1-\sqrt{1-\mu_{\text {ave }, l_{p}}}\right)
\end{aligned}
$$

The correlation between the pit depth and equivalent uniform corrosion depth calculated from the above two methods is plotted in Fig. 8. It shows that the points for $x_{u, \text { ave }}$ are mostly above those for $x_{u, \max }$, which indicates that the pitting factor calculated by $\alpha_{\max }=x_{p} / x_{u, \max }$ is smaller than that of $\alpha_{\text {ave }}=x_{p} / x_{u, \text { ave }}$. The ratio $x_{p} / x_{u, \max }$ or $x_{p} / x_{u, \text { ave }}$ is not the distance of cross-sections on the rebar from the bar's end outside the concrete

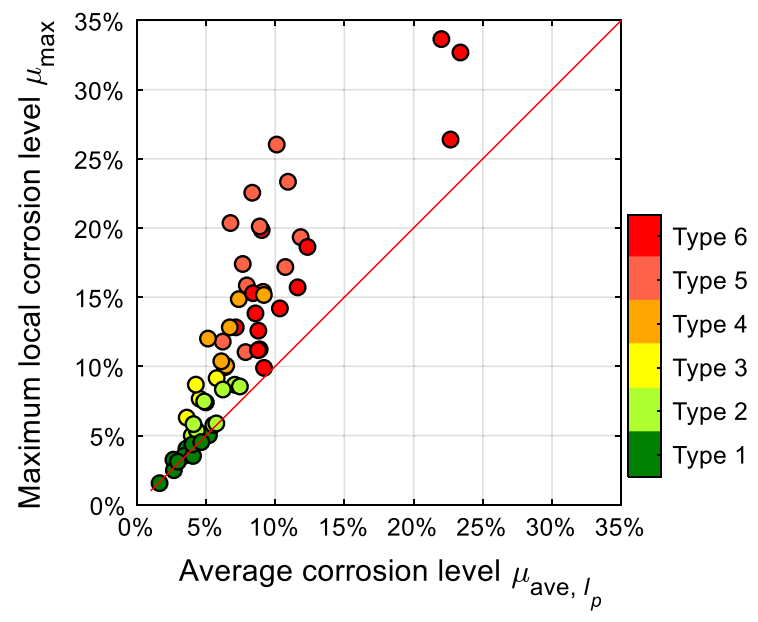

Fig. 7 Maximum local corrosion level versus average corrosion level in the pit

a constant value (in other words, the data points in Fig. 8 are not linear in their placement) as the pitting factor varies among bars. The histograms of the pitting factor from the two methods were obtained, in order to determine a typical pitting factor value for the bars in this study (see Fig. 9). The results demonstrate that the maximum probability for the pitting factor falls between 4 and 6 for $\alpha_{\max }$ and 8-10 for $\alpha_{\text {ave }}$. As $\alpha_{\text {ave }}$ (calculated from the average steel loss in the pit) is closer to the definitions with traditional methods in the literature, its value $(8-10)$ is considered as the pitting factor for rebars in this study and represents highly localised pitting according to [32]. 


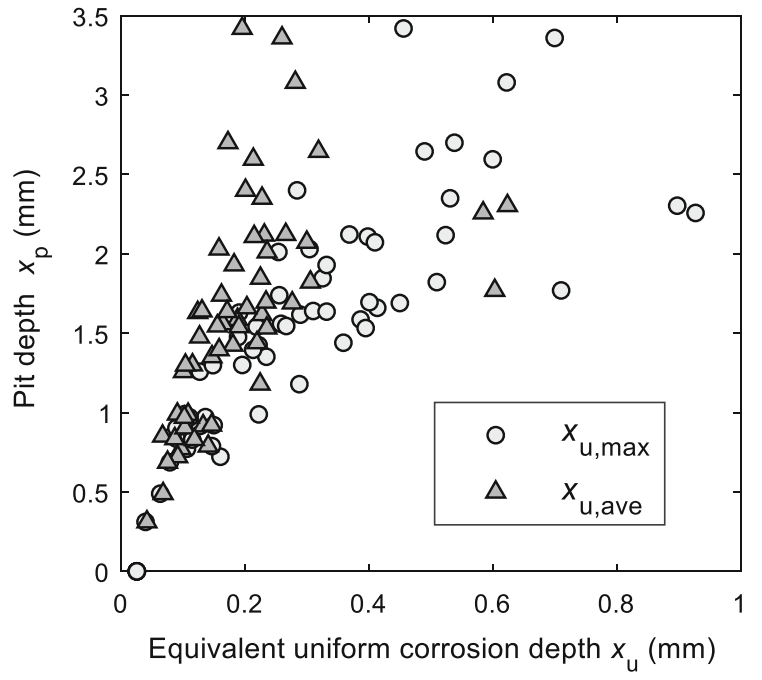

Fig. 8 Pit depth versus equivalent uniform corrosion depth

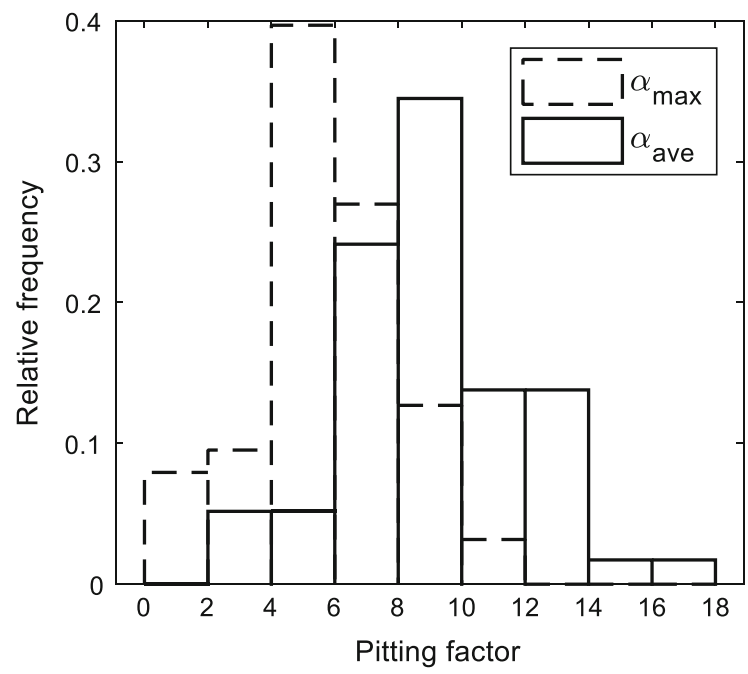

Fig. 9 Histograms of the pitting factor

\subsection{Comparison of maximum local corrosion level $\mu_{\max }$}

In this section, the maximum local corrosion levels of rebars from all specimens are compared and statistically analysed to examine the effects of crack width, loading condition and fibre reinforcement. Figure 10 shows $\mu_{\max }$ of bars in all beams, with the colour representing the pit type defined in Table 3. For bars with induced longitudinal cracks, the corresponding transverse and longitudinal crack widths are labelled in black and red fonts respectively (note: only crack widths on some of the beams were recorded, as mentioned in Sect. 2.3 and Table 2). Three bars in the same beam are placed together, with the sequence of three bars corresponding to their locations (such as corner bar or middle bar) in the beam, as indicated in the figure. The ST beam under the "cyclic" condition with target crack $0.4 \mathrm{~mm}$ was accidentally overloaded during pre-loading, causing the maximum crack width to be about $0.8 \mathrm{~mm}$. The results of that beam are therefore omitted. Also, one bar in each of PL-U0.4, ST-L0.4 and SY-U0.1 were bent too much during the extraction process. Consequently, their local corrosion levels could not be properly evaluated, as it was difficult to straighten the 3D-scanned bar meshes and obtain accurate cross-sections based on the scan results.

As observed in Fig. 10, $\mu_{\max }$ of bars in the same beam varied significantly. The largest $\mu_{\max }$ for each beam was mostly on the corner bar, with only one exception. This was anticipated as chloride can diffuse from both the tension surface and the side surface facing the corner bar. Corrosion-induced surface cracks were also generated above many corner bars, as shown in Figs. 3 and 4. This also accelerated the local corrosion on the corner bar. The effect of corrosion-induced cracks will be described further in Sect. 4.4.

\subsubsection{Influence of loading condition}

Figure 11 shows the average value of $\mu_{\max }$ for bars in the same beam, with the standard deviation represented by the error bars. For PL and ST series involving all three loading conditions ("unloaded", "cyclic", and "loaded"), the average $\mu_{\max }$ is compared for beams with the same mix type and target crack width but different loading conditions. In the four comparison groups, the "unloaded" condition resulted in larger average $\mu_{\max }$ than the "cyclic" and "loaded" conditions for PL-0.1, PL-0.4 and ST-0.4 groups. At the same time, just for ST-0.1 group, the "loaded" beam had the largest average $\mu_{\max }$ among the three loading conditions. For HY beams, the average $\mu_{\max }$ was similar for the "unloaded" and "cyclic" loading types. These results contradict the findings in [19], where the maximum local corrosion levels under the "loaded" and "cyclic" conditions were mostly greater than for the "unloaded" condition. The differing results may be related to the 

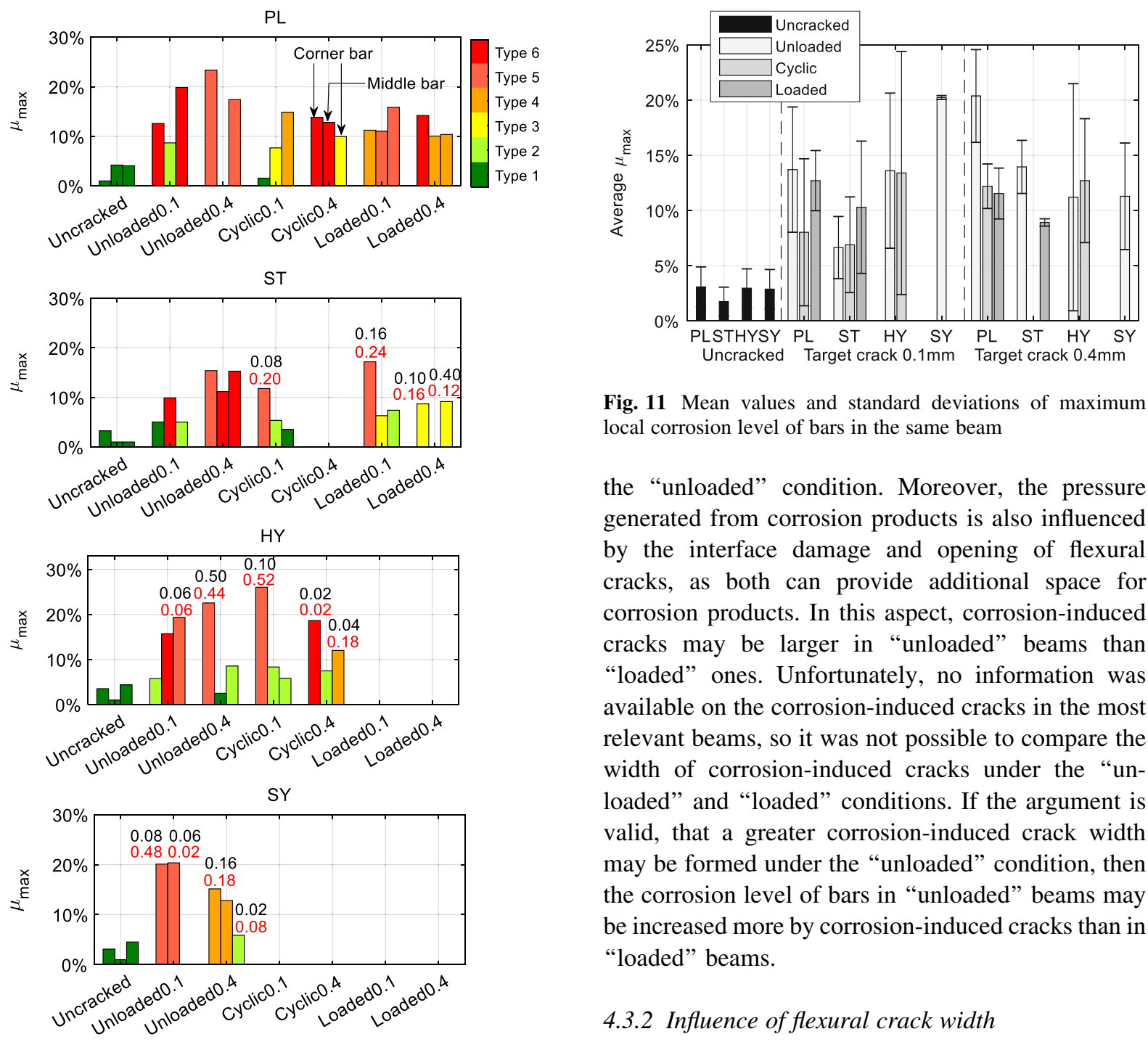

Fig. 10 Maximum local corrosion levels for all bars

additional storage period of nearly 2 years for specimens in this study compared to those in [19]. However, the mechanism behind this needs to be further explored.

From Fig. 10, pit Types 5 and 6, both of which have a locally deep pit depth, are dominant for the "unloaded" condition, whereas more pits belonging to Types 3 and 4 (both of which have long pits but shallow depth) were found for the "loaded" case. The long pit length formed on bars in "loaded" beams may relate to the greater extent of slip and separation between concrete and steel, while a more localised pit is likely to form where lesser damage is caused under

Fig. 11 Mean values and standard deviations of maximum local corrosion level of bars in the same beam

the "unloaded" condition. Moreover, the pressure generated from corrosion products is also influenced by the interface damage and opening of flexural cracks, as both can provide additional space for corrosion products. In this aspect, corrosion-induced cracks may be larger in "unloaded" beams than "loaded" ones. Unfortunately, no information was available on the corrosion-induced cracks in the most relevant beams, so it was not possible to compare the width of corrosion-induced cracks under the "unloaded" and "loaded" conditions. If the argument is valid, that a greater corrosion-induced crack width may be formed under the "unloaded" condition, then the corrosion level of bars in "unloaded" beams may be increased more by corrosion-induced cracks than in "loaded" beams.

\subsubsection{Influence of flexural crack width}

From Figs. 10 and 11, it is obvious that uncracked beams have a smaller $\mu_{\max }$ than pre-cracked ones. It should be noted that the pitting corrosion at the ends of bars in uncracked beams was not considered. No obvious dependency of $\mu_{\max }$ on the target crack width of 0.1 and $0.4 \mathrm{~mm}$ was observed in Figs. 10 and 11 . Further, the distribution of $\mu_{\max }$ values is compared for bars in uncracked and cracked beams. The results from the ST beam cyclically loaded by accident to an $0.8 \mathrm{~mm}$ crack width were also used, as they contribute to the limited available data for $\mu_{\max }$ under larger crack widths. Figure 12a shows the histograms of $\mu_{\max }$ for uncracked (zero crack width), target cracks of 0.1 and $0.4 \mathrm{~mm}$ and a maximum crack of $0.8 \mathrm{~mm}$. From Fig. 12a, all bars in the uncracked beams had $\mu_{\max }$ 
value of less than $10 \%$ and the three bars under target crack width of $0.8 \mathrm{~mm}$ all had $\mu_{\max }$ greater than $20 \%$. However, the relative frequency distribution of $\mu_{\max }$ differed, to merely a small extent, for target crack widths of 0.1 and $0.4 \mathrm{~mm}$.

\subsubsection{Influence of fibres}

From Fig. 11, it can be seen that ST series consistently showed a lower average $\mu_{\max }$ than PL series under the same loading condition and target crack width. HY series and SY series had similar or lower average $\mu_{\max }$ than PL series under the target crack width of $0.4 \mathrm{~mm}$. However, the opposite was true under the target crack width of $0.1 \mathrm{~mm}$. This suggests fibre reinforcement may be more effective in reducing the corrosion level when the achieved crack width is larger.

Figure $12 \mathrm{~b}$ gives the histograms of $\mu_{\max }$ for the four concrete mix series. For PL series, the relative number of bars with $\mu_{\max }$ of $10-20 \%$ was higher than that with $\mu_{\max }$ lower than $10 \%$. However, the opposite was the case for fibre series. This shows that more bars from beams in PL series presented severe pitting corrosion than those in FRC series. However, the relative frequency of $\mu_{\max }$ of $20-30 \%$ was greater for HY and SY than PL and ST. Looking back to Fig. 10, two corner rebars in the HY series have largely different $\mu_{\max }$, but were under the same loading and exposure conditions. Further, Fig. 11 shows that HY series had

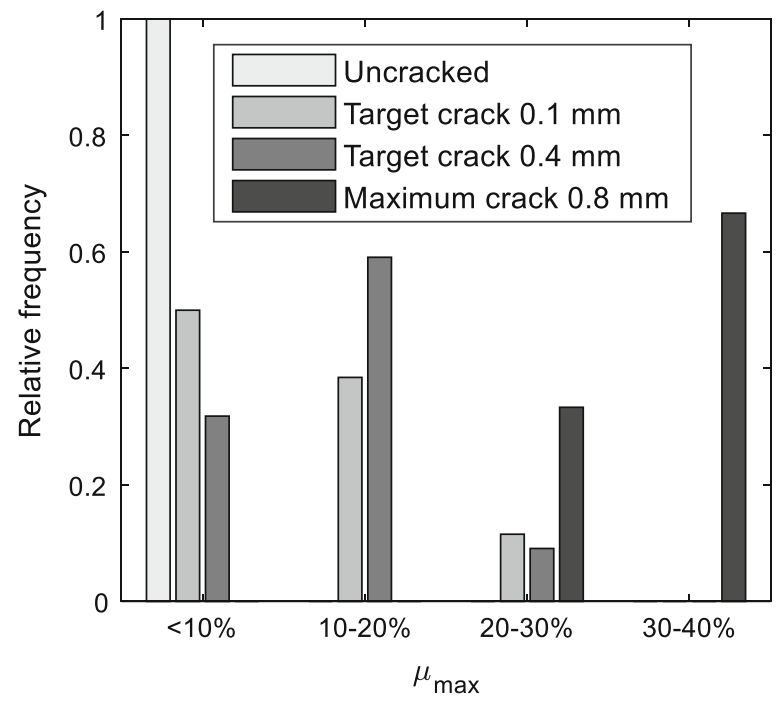

(a) larger standard deviation of $\mu_{\max }$ than ST and SY series. It is therefore inferred that the fibre distribution may be uneven in the HY series, causing locally severe damage during pre-loading and severe pitting corrosion on one of the bars in a beam. The high relative frequency of $\mu_{\max }$ of $20-30 \%$ in SY series is because the total specimen number for SY beams is only three (including one "uncracked" beam and two "unloaded" beams) and $\mu_{\max }$ in SY-U0.1 is slightly greater than $20 \%$, as seen from Fig. 10. More specimens need to be studied before conclusions can be drawn regarding the effect of fibres on maximum local corrosion level.

It should be noted that with a defined target crack width, loading condition type and mix proportion, only one beam was studied although there were three rebars were involved in one beam. Replicated specimens under the same condition need to be further studied to verify the tendencies found in this study, as suggested in [33] for the recommended practice when reporting corrosion experimental data.

\subsection{Discussions on the role of longitudinal cracks}

\subsubsection{Correlation between maximum local corrosion level and longitudinal crack width}

Longitudinal crack widths were measured on four cracked ST beams and all the cracked HY and SY

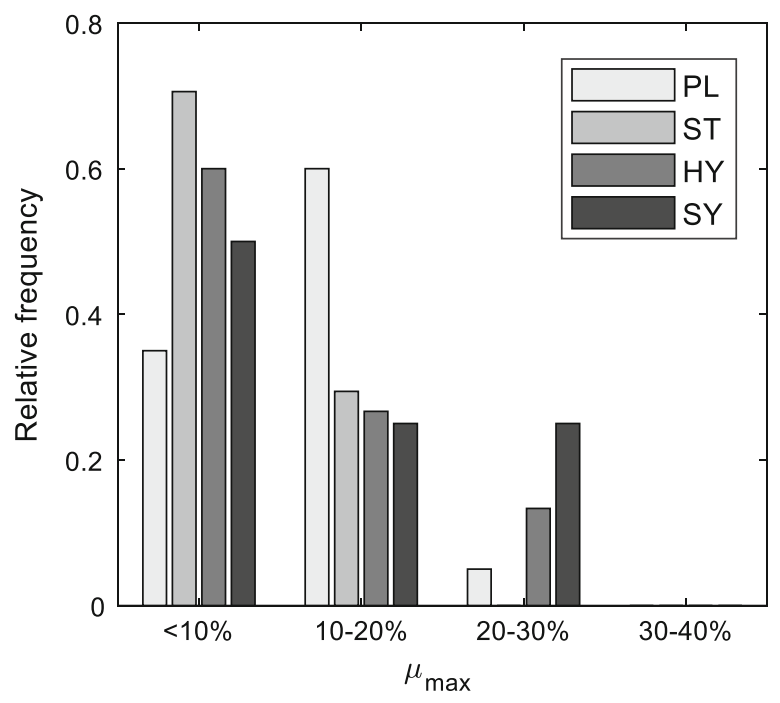

(b)

Fig. 12 Histograms of maximum local corrosion level: a under different maximum crack widths; $\mathbf{b}$ for different mixes 
beams, see Table 2. Thus, only results from those beams are discussed. The maximum width of each corrosion-induced crack above the same corrosion pit was used. For beams in which longitudinal cracks had been found at the same pit on both the tension surface and side surface (see SY-U0.4 in Fig. 4), the maximum longitudinal crack width was taken. Figure 13 presents the correlation between longitudinal crack width and maximum local corrosion level of the corrosion pit beneath the crack. Whenever no corrosion-induced cracks were formed, the longitudinal crack width was taken as zero.

Figure 13 shows that, apart from four of them, most points with non-zero longitudinal cracks lie around a trend line. Although the cracking resistance parameters (the tensile strength $f_{c t}$ and fracture behaviour) of the three types of FRC are different (given in [19]), their data points are still close to the same fitting line. It is also found that some pits with a high maximum local corrosion level of $10-35 \%$ did not induce longitudinal cracks. Those points are mainly from middle bars or have Type 6 pits. For the middle bar in a beam, the corrosion-induced cracks are more prone to develop towards the neighbouring bars rather than propagating to the cover surface. This is due to the confinement provided by the surrounding concrete, as revealed in [34]. The dependence of cracking

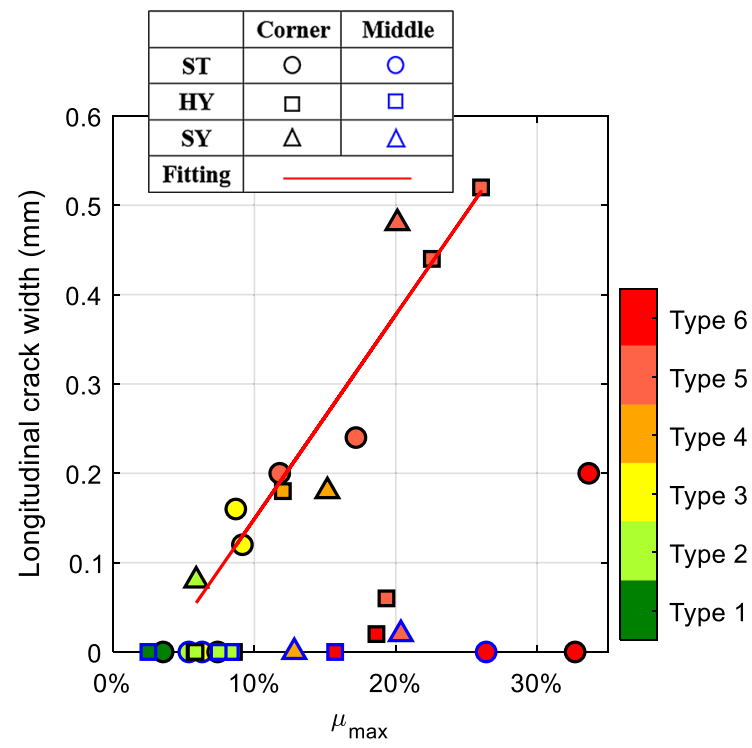

Fig. 13 Longitudinal crack width versus maximum local corrosion level behaviour on local corrosion length and pitting corrosion pattern has been studied numerically in [35], showing the tendency for shorter corrosion lengths to cause shorter and smaller corrosion cracks. Another study [36] showed experimentally that the required rust thickness of localised corrosion for cover cracking increased as the anodic length decreased. For deep but short elliptical pits, the internal pressure arising from the limited volume of corrosion products may not be sufficient to damage the concrete cover. The first example in Fig. 5 illustrates such a case. The maximum local corrosion level was $18.6 \%$ while the longitudinal crack width was only $0.02 \mathrm{~mm}$. An important implication is that a rebar may lose a large amount of cross-sectional area in a localised pit, but no large corrosion cracks are produced which might give a warning. This is of major importance for structural condition assessment.

\subsubsection{Correlation between pit volume and longitudinal crack width}

There is an interaction between longitudinal cracks and pit volume. On the one hand, longitudinal cracks are caused by the volume accumulation of corrosion products. On the other, as longitudinal cracks grow, more steel surface is exposed to chloride and starts to corrode; this increases the rebar volume loss. Figure 14 shows the correlation between pit volume

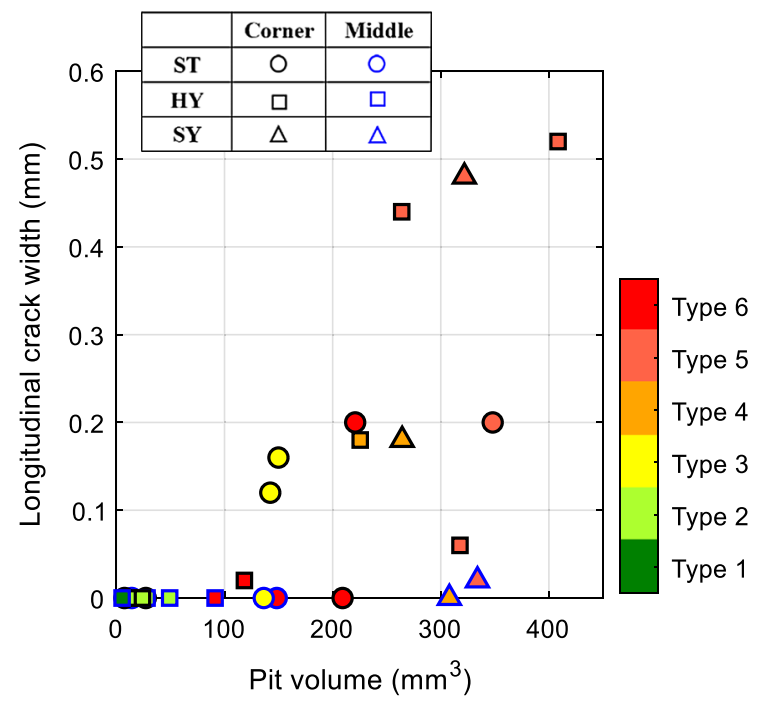

Fig. 14 Longitudinal crack width versus pit volume 


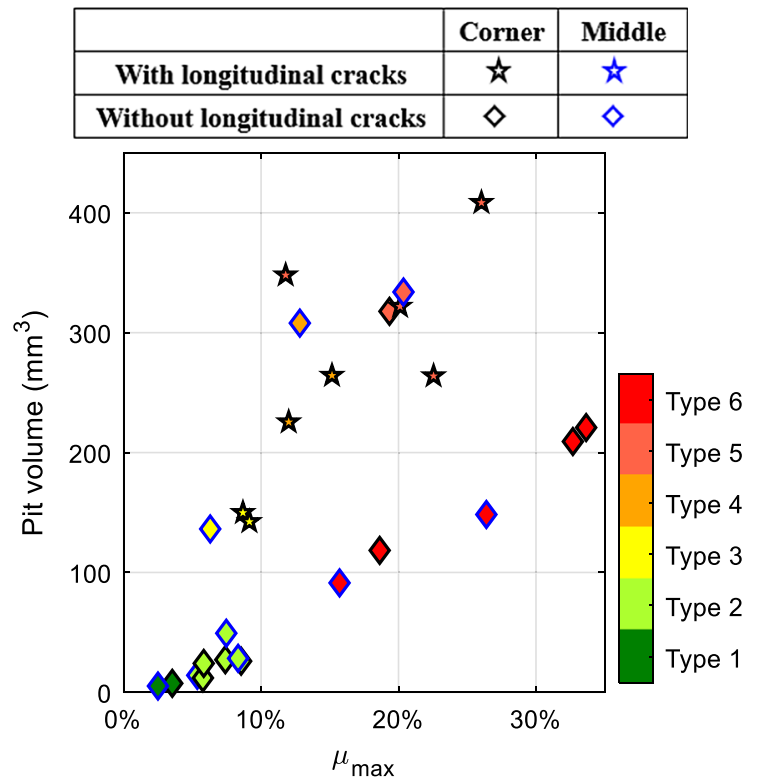

Fig. 15 Pit volume versus maximum local corrosion level

and longitudinal crack width, with the symbol colour representing the pit type. As can be seen, the correlation depends on the bar location (such as corner or middle bar) and pit type. For a similar pit volume, a larger longitudinal crack on the surface was induced by the corner rebar than the middle rebar. Most pits under longitudinal cracks are Types 3, 4 and 5, which have long pits.

The correlation between maximum local corrosion level and pit volume is examined in Fig. 15. In general, the pits under longitudinal cracks have greater volume loss than those without longitudinal cracks. This may be explained by the larger surface area of steel that is exposed to the external environment when there is a longitudinal crack as opposed to a transverse crack. However, the correlation between the pit volume and maximum local corrosion level looks scattered. The maximum local corrosion level can vary a lot for the same pit volume. For a Type 6 pit, the pit volume is smaller than in Types 4 and 5 with similar maximum local corrosion levels. Therefore, the correlation between pit volume and maximum local corrosion level depends greatly on the pit morphology. This indicates that the maximum local corrosion level cannot be solely derived from total steel loss (or pit volume).

\subsubsection{Hypothesis of the time-varying influence of cracks on the evolution of pit morphology}

Inspired by the above discussions, a time-varying scenario for the corrosion propagation in cracked concrete will now be outlined, as shown in Fig. 16. Before corrosion initiation, transverse cracks existing in concrete provide preferential paths for chloride, oxygen and moisture and lead to localised pitting corrosion near the cracks. This corresponds to Stage I in Fig. 16. The long length of the blue arrow above the transverse cracks shows that the permeability and diffusivity are greater there than in the uncracked region. Microcell inside the pit and macrocell outside it on the uncorroded steel determine the local corrosion rate in the pit. The macrocell corrosion rate may be influenced by several factors such as the concrete resistivity and porosity (both related to the binder type), the cover depth, etc. Most important factors depend on whether the rate-limiting factor of the corrosion reaction is controlled by the ohmic process or cathodic process [23].

In Stage II, the expansion pressure generated by the pitting corrosion products induces cover cracking. The longitudinal cracks, in turn, impact the pitting corrosion by providing new preferential paths for chloride, oxygen and moisture in this stage. Few studies have been conducted on the influence of longitudinal cracks on the corrosion rate, contrary to a lot of studies on the influence of transverse cracks. In a previous study [21], greater corrosion rate has been reported in concrete with longitudinal cracks than in concrete with transverse cracks. However, it should be noted that the local corrosion rate may be underestimated if the whole exposed steel surface is used instead of the real anodic area to calculate the corrosion rate [21, 22], as the corrosion is usually localised at the tip of transverse cracks. In addition, Poursaee and Hansson [21] found that in the presence of longitudinal cracks, the resistivity of different types of binder was not an influencing factor in the corrosion rate of rebars. Since the influence of various factors, such as the chloride concentration, oxygen concentration and concrete resistivity, on the corrosion reactions is complex, it is challenging to quantify the influence of transverse and longitudinal cracks on the corrosion propagation rate. 

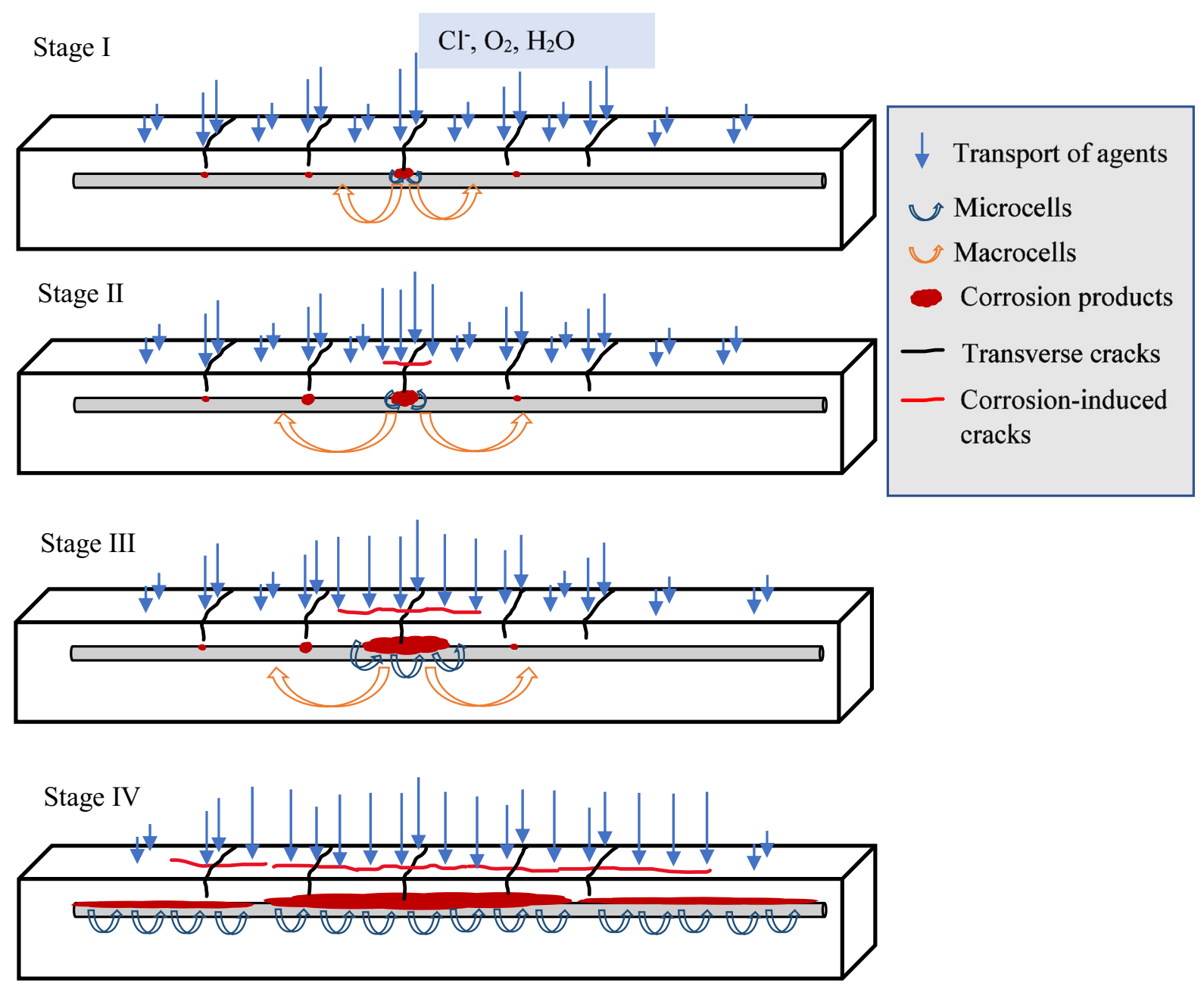

Fig. 16 Hypothesis for the interplay between transverse and longitudinal cracks and corrosion. Stage I: transverse cracks induce localised pitting corrosion. Stage II: longitudinal cracks start to form. Stage III: longitudinal cracks develop and

In Stage III, the longitudinal cracks develop further. The anodic area thereby increases which, in turn, causes the longitudinal cracks to develop further in width and length. The specimens in the present study were between Stages II and III. The mutual interaction between pit development and corrosion-induced cracking will continue with time. Possibly, if there are longitudinal cracks caused by other pits along the beam length, these will interconnect during crack propagation. Eventually, the longitudinal cracks will extend along the whole beam and corrosion pitting will distribute along the whole reinforcement, indicating Stage IV. It is also possible that after long-term exposure to chloride, the chloride content entering corrosion length increases. Stage IV: longitudinal cracks spread along the whole beam length and corrosion becomes more general

through the uncracked cover may be enough to activate a major range of corrosion sites.

A previous study [24] examined the edge beams of a girder bridge (the Stallbacka Bridge in Sweden). Having been exposed to natural corrosion for 32 years, the corroded bars in places with splitting cracks or cover spalling showed corrosion across significant lengths of the bars. This gives a practical example of the corrosion and cracking state in Stage IV. A previous study in [10] has provided experimental evidence for the evolution of the crack and corrosion pattern from Stages III to IV, by analysing two beams that had been subjected to sustained load in a chloride environment for 14 and 23 years, 
respectively. The steel cross-sectional loss in the beam exposed for 14 years was concentrated in only the middle part along the length of reinforcements. However, the cross-sectional loss along the reinforcements in the beam exposed for 23 years was major over the entire bar length, except the end region. From the cracking maps of one beam drawn at the 14th, 19th and 23rd year, the extent of longitudinal cracks on the beam was seen to increase with years of exposure. Another study in [37] examined the corrosion characteristics of a 4-year, naturally corroded concrete beam which was loaded to have the maximum transverse crack width of $0.2 \mathrm{~mm}$ before exposed to chloride. This beam presented longitudinal cracks along its entire length and major cross-sectional loss along the whole length of the reinforcement except the end. This corresponds to Stage IV in Fig. 16. The extent of corrosion-induced cracking and corrosion level of rebars in their specimen was much greater than that in this study although the exposure time was close to the one in this study. This is probably due to the thin concrete cover and corrosion of stirrups, as indicated by the authors.

\subsubsection{Implications for the long-term durability of FRC structures}

Compared to plain reinforced concrete, fibre-reinforced concrete has improved cracking resistance to mechanical loading and corrosion expansion. To evaluate the durability of FRC structures in a chloride environment, the influences of various types of cracks on the steel corrosion process should be considered.

Adding fibres are beneficial to form more tortuous internal cracking and reduce concrete-steel interfacial damage under service loading. A recent study (reported in [20]) revealed that interfacial damage may increase corrosion activity (in terms of the total rebar mass loss and corrosion length). This was done by comparing specimens with both transverse cracks and interfacial damage to those with transverse cracks only. However, the maximum local corrosion level of their specimens was not reported and the corrosion time investigated was less than a year. The influence of interfacial damage has been discussed in Sect. 4.3.1 of the present study, by comparing the maximum local corrosion level of bars in beams under the "unloaded" and "loaded" conditions. This was because the interfacial damage was postulated as being less for the "unloaded" condition than for the "loaded" one. The results showed that, in most cases, the maximum local corrosion level of bars in beams with the "unloaded" condition was greater than for the "loaded" condition. Further studies are needed to confirm the effect of interfacial damage on corrosion propagation.

Moreover, FRC may delay cover cracking under corrosion expansion due to the additional confinement provided by fibres [38, 39]. Undoubtedly, longitudinal cracks may greatly aggravate the total steel loss (as in pit volume) by increasing the anodic length. Even so, the maximum cross-sectional loss may develop more slowly when the corrosion length is increased. The correlation between maximum local corrosion level and pit volume was found to depend on the pit morphology. As the way in which pit morphology influences structural behaviour is still unresolved, the benefits afforded by concrete structures reinforced with steel bars and fibres (as compared to conventional reinforced concrete) remain to be quantified. Further theoretical studies covering the local corrosion rate prediction from electrochemical reaction and transport process in cracked concrete, as well as experimental work on specimens exposed for longer periods, are needed to assess the overall performance of FRC in a chloride environment.

\section{Conclusions}

This paper studied the corrosion pattern and characteristics of rebars in un- and pre-cracked plain and fibre-reinforced concrete beams which were subjected to natural corrosion for more than 3 years. A 3Dscanning technique was used to characterise the pit morphology. The influences of loading type, fibres, flexural cracks and corrosion-induced cracks on the maximum local corrosion level and pit morphology were studied. The following conclusions were drawn:

1. The pre-cracked beams showed various degrees of pitting corrosion, with the maximum local corrosion level in almost all bars significantly greater than for bars in uncracked beams. Still, no correlation was found between the maximum flexural crack width (nominally 0.1 and $0.4 \mathrm{~mm}$ ) and the maximum local corrosion level. However, one of the beams was occasionally pre-cracked to 
$0.8 \mathrm{~mm}$. The three bars in this beam had the highest maximum local corrosion level of all bars: greater than $20 \%$.

2. All the beams in the steel fibre series had lower average maximum local corrosion levels than the counterparts of plain series. Hybrid fibre series and synthetic fibre series showed similar or lower average maximum local corrosion levels than their plain series counterparts for the larger crack width $(0.4 \mathrm{~mm})$. The bars in the hybrid fibre series showed a large standard deviation, which may have been due to uneven fibre distribution.

3. In three out of four comparison groups, the bars had a higher average maximum local corrosion level in the "unloaded" condition than in the "loaded" one. This contradicts earlier findings. A possible explanation is that the greater interfacial damage in the "loaded" condition induced a longer anodic site and slower growth of the pit depth than in the "unloaded" condition. Further studies are required to understand the influence of interface damage on the corrosion propagation.

4. When present, the maximum longitudinal crack width had a linear correlation to the maximum local corrosion level for most pits. However, some severe pits did not induce any longitudinal crack, or the induced corrosion crack was very small. It is important to note that pitting corrosion did not always induce longitudinal cracks; in practice, the maximum local corrosion level in pitting corrosion may be underestimated if it is assessed on the basis of longitudinal crack width.

5. A hypothesis about the time-dependent interplay between transverse and longitudinal cracks and corrosion development was formulated as follows. Transverse cracks generated before the corrosion onset lead to localised pitting corrosion close to the cracks. When corrosion-induced cracks appear, the pitting length increases and total mass loss greatly increases. However, the maximum cross-sectional area loss has no unique correlation with the total mass loss in the pit.

Acknowledgements Open access funding provided by Chalmers University of Technology. The work reported in this paper has been supported by: the Swedish Transport Administration, under the Project Grant TRV 2018/36506; the construction industry's organisation for research and development (SBUF) under the Project Grant 13683; Chalmers University of Technology; Thomas Concrete Group; and Cementa $\mathrm{AB}$ (Heidelberg Cement Group).

\section{Compliance with ethical standards}

Conflict of interest The authors declare that they have no conflict interest.

Open Access This article is licensed under a Creative Commons Attribution 4.0 International License, which permits use, sharing, adaptation, distribution and reproduction in any medium or format, as long as you give appropriate credit to the original author(s) and the source, provide a link to the Creative Commons licence, and indicate if changes were made. The images or other third party material in this article are included in the article's Creative Commons licence, unless indicated otherwise in a credit line to the material. If material is not included in the article's Creative Commons licence and your intended use is not permitted by statutory regulation or exceeds the permitted use, you will need to obtain permission directly from the copyright holder. To view a copy of this licence, visit http://creativecommons.org/licenses/by/4.0/.

\section{Appendix}

See Figs. 17 and 18.

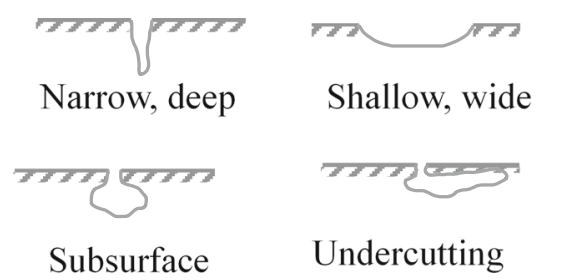

Fig. 17 Sketch of common pit shapes; redrawn from [25]

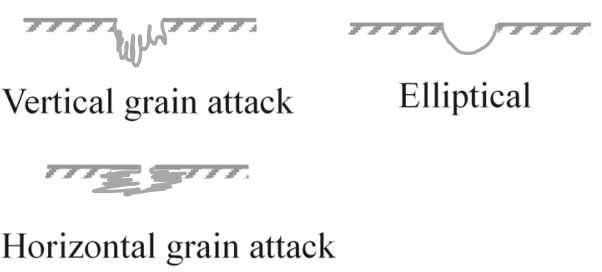


(a)

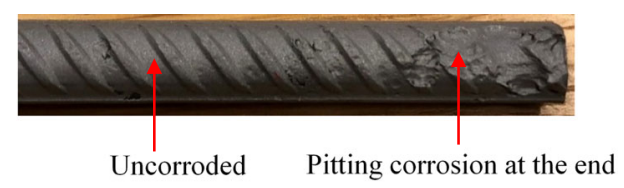

(b)

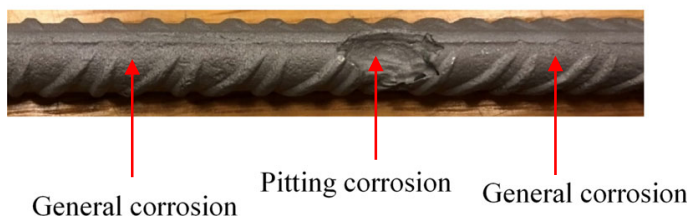

Fig. 18 Corrosion pictures: a pitting at the end; $\mathbf{b}$ general corrosion and pitting corrosion

\section{References}

1. Tang SW, Yao Y, Andrade C, Li Z (2015) Recent durability studies on concrete structure. Cem Concr Res 78:143-154

2. Bentur A, Berke N, Diamond S (1997) Steel corrosion in concrete: fundamentals and civil engineering practice. CRC Press, Boca Raton

3. Wang K, Jansen DC, Shah SP, Karr AF (1997) Permeability study of cracked concrete. Cem Concr Res 27(3):381-393

4. Rodriguez OG, Hooton RD (2003) Influence of cracks on chloride ingress into concrete. ACI Mater J 100(2):120-126

5. Schieß1 P, Raupach M (1997) Laboratory studies and calculations on the influence of crack width on chloride-induced corrosion of steel in concrete. ACI Mater J 94(1):56-61

6. Otieno M, Alexander M, Beushausen H-D (2010) Corrosion in cracked and uncracked concrete-influence of crack width, concrete quality and crack reopening. Mag Concr Res 62(6):393-404

7. Boschmann Käthler C, Angst UM, Wagner M, Larsen CK, Elsener B (2017) Effect of cracks on chloride-induced corrosion of steel in concrete-a review: Etatsprogrammet Varige konstruksjoner 2012-2015. ETH Zurich

8. Scott A, Alexander M (2007) The influence of binder type, cracking and cover on corrosion rates of steel in chloridecontaminated concrete. Mag Concr Res 59(7):495-505

9. Otieno M, Beushausen H, Alexander M (2016) Resistivitybased chloride-induced corrosion rate prediction models and hypothetical framework for interpretation of resistivity measurements in cracked RC structures. Mater Struct 49(6):2349-2366

10. Zhang R, Castel A, François R (2009) The corrosion pattern of reinforcement and its influence on serviceability of reinforced concrete members in chloride environment. Cem Concr Res 39(11):1077-1086

11. Francois R, Khan I, Vu NA, Mercado H, Castel A (2012) Study of the impact of localised cracks on the corrosion mechanism. Eur J Environ Civ Eng 16(3-4):392-401

12. FIB (2006) Model code for service life design, vol 34. Fédération Internationale du Béton, Lausanne

13. Eurocode 2: Design of concrete structures-Part 1-1: general rules and rules for buildings: EN 1992-1-1 (2004). European Committee for Standardization
14. Stang H, Aarre T (1992) Evaluation of crack width in FRC with conventional reinforcement. Cem Concr Compos 14(2):143-154

15. Jansson A, Flansbjer M, Löfgren I, Lundgren K, Gylltoft K (2012) Experimental investigation of surface crack initiation, propagation and tension stiffening in self-compacting steel-fibre-reinforced concrete. Mater Struct 45(8):1127-1143

16. Mihashi H, Ahmed SFU, Kobayakawa A (2011) Corrosion of reinforcing steel in fiber reinforced cementitious composites. J Adv Concr Technol 9(2):159-167

17. Blunt J, Jen G, Ostertag C (2015) Enhancing corrosion resistance of reinforced concrete structures with hybrid fiber reinforced concrete. Corros Sci 92:182-191

18. Berrocal CG, Löfgren I, Lundgren K, Tang L (2015) Corrosion initiation in cracked fibre reinforced concrete: influence of crack width, fibre type and loading conditions. Corros Sci 98:128-139

19. Berrocal CG, Löfgren I, Lundgren K (2018) The effect of fibres on steel bar corrosion and flexural behaviour of corroded RC beams. Eng Struct 163:409-425

20. Hay R, Ostertag CP (2019) Influence of transverse cracks and interfacial damage on corrosion of steel in concrete with and without fiber hybridization. Corrosion Sci 153:213-224

21. Poursaee A, Hansson CM (2008) The influence of longitudinal cracks on the corrosion protection afforded reinforcing steel in high performance concrete. Cem Concr Res 38(8-9):1098-1105

22. Marcotte T, Hansson C (2003) The influence of silica fume on the corrosion resistance of steel in high performance concrete exposed to simulated sea water. J Mater Sci 38(23):4765-4776

23. Hornbostel K, Elsener B, Angst UM, Larsen CK, Geiker MR (2017) Limitations of the use of concrete bulk resistivity as an indicator for the rate of chloride-induced macrocell corrosion. Struct Concr 18(2):326-333

24. Tahershamsi M, Fernandez I, Lundgren K, Zandi K (2017) Investigating correlations between crack width, corrosion level and anchorage capacity. Struct Infrastruct Eng 13(10):1294-1307

25. Bhandari J, Khan F, Abbassi R, Garaniya V, Ojeda R (2015) Modelling of pitting corrosion in marine and offshore steel structures-A technical review. J Loss Prev Process Ind 37:39-62

26. Suzuki K, Ohno Y, Praparntanatorn S, Tamura H (1990) Mechanism of steel corrosion in cracked concrete. In: The 3rd international symposium on corrosion of reinforcement in concrete construction, Warwickshire

27. Marcos-Meson V, Michel A, Solgaard A, Fischer G, Edvardsen C, Skovhus TL (2018) Corrosion resistance of steel fibre reinforced concrete-a literature review. Cem Concr Res 103:1-20

28. Arya C, Ofori-Darko F (1996) Influence of crack frequency on reinforcement corrosion in concrete. Cem Concr Res 26(3):345-353

29. François R, Laurens S, Deby F (2018) Corrosion and its consequences for reinforced concrete structures. Elsevier, Amsterdam

30. Rodriguez J (1996) Corrosion of reinforcement and service life of concrete structures. In: Proceedings of 7th international conference on DBMC, pp 117-126 
31. Vidal T, Castel A, Francois R (2004) Analyzing crack width to predict corrosion in reinforced concrete. Cem Concr Res 34(1):165-174

32. Gonzalez J, Andrade C, Alonso C, Feliu S (1995) Comparison of rates of general corrosion and maximum pitting penetration on concrete embedded steel reinforcement. Cem Concr Res 25(2):257-264

33. Isgor OB, Angst U, Geiker M, Halmen C, Hansson C, Pacheco J, Tepke D, Trejo D, Vaddey P (2019) Recommended practice for reporting experimental data produced from studies on corrosion of steel in cementitious systems. RILEM Tech Lett 4:22-32

34. Chen E, Leung CK (2015) Finite element modeling of concrete cover cracking due to non-uniform steel corrosion. Eng Fract Mech 134:61-78

35. Tran K, Nakamura H, Kunieda M, Ueda N (2011) Three dimensional behaviour of concrete cracking due to rebar corrosion. Proc Eng 14:419-426
36. Torres-Acosta AA, Sagues AA (2004) Concrete cracking by localized steel corrosion-geometric effects. ACI Mater J 101(6):501-507

37. Fu C, Jin N, Ye H, Jin X, Dai W (2017) Corrosion characteristics of a 4-year naturally corroded reinforced concrete beam with load-induced transverse cracks. Corros Sci 117:11-23

38. Solgaard AOS, Michel A, Geiker M, Stang H (2013) Concrete cover cracking due to uniform reinforcement corrosion. Mater Struct 46(11):1781-1799

39. Berrocal CG, Fernandez I, Lundgren K, Löfgren I (2017) Corrosion-induced cracking and bond behaviour of corroded reinforcement bars in SFRC. Compos B Eng 113:123-137

Publisher's Note Springer Nature remains neutral with regard to jurisdictional claims in published maps and institutional affiliations. 